\title{
Executive Compensation and Misconduct: Environmental Harm
}

\section{Citation}

Minor, Dylan. "Executive Compensation and Misconduct: Environmental Harm." Harvard Business School Working Paper, No. 16-076, January 2016.

\section{Permanent link}

http://nrs.harvard.edu/urn-3:HUL.InstRepos:25538424

\section{Terms of Use}

This article was downloaded from Harvard University's DASH repository, and is made available under the terms and conditions applicable to Other Posted Material, as set forth at http:// nrs.harvard.edu/urn-3:HUL.InstRepos:dash.current.terms-of-use\#LAA

\section{Share Your Story}

The Harvard community has made this article openly available.

Please share how this access benefits you. Submit a story.

\section{Accessibility}




$$
\text { H A R VAR D B US INESS SCHOOL }
$$

\section{Executive Compensation and Misconduct: Environmental Harm}

Dylan Minor

Working Paper 16-076 


\title{
Executive Compensation and Misconduct: Environmental Harm
}

\author{
Dylan Minor
}

Harvard Business School

Working Paper 16-076 


\title{
Executive Compensation and Misconduct: Environmental Harm *
}

\author{
Dylan Minor \\ Harvard Business School
}

January 2016

\begin{abstract}
We explore the relationship between managerial incentives and misconduct using the setting of environmental harm. We find that high powered executive compensation can increase the odds of environmental law-breaking by $40-60 \%$ and the magnitude of environmental harm by over $100 \%$. We document similar results for the setting of executive compensation and illegal financial accounting. Finally, we outline some managerial and policy implications to blunt these adverse incentive effects.
\end{abstract}

Keywords: executive compensation, corporate governance, misconduct, environmental performance, accounting scandal, sustainable finance

JEL Codes: G01, G31, J33, K32

*I thank Jennifer Brown, Georgy Egorov, Caroline Flammer, Mitchell Hoffman, Michelle Lowry, David Matsa, Nicola Persico, Max Schanzenbach, and Jun Yang for their helpful comments. Also thanked are the participants at American Law and Economics Association Meetings, Conference on Empirical Legal Studies, the CRES workshop (Washington University, St. Louis), Institutions and Innovation conference (Harvard Business School), Natural Experiments Workshop (Munich), and seminar participants at the Kellogg School of Management and Northwestern Law School. I thank Jared Petravicius for his excellent research assistance and the Ford Center for Global Citizenship for financial support of the project. 
The recent passage of the Paris Agreement generated by the 2015 United Nations Climate Change Conference highlights the global consensus on the importance of limiting environmental harm. Businesses play a significant role in environmental outcomes (Dowell, Hart, and Yeung [2000]). Many businesses are substantial contributors to the problem of climate change. Recognizing the opportunity for business to also be part of the solution, a coalition of global companies representing over $\$ 1$ trillion of revenue recently urged companies to become catalysts for reducing negative environmental impacts. ${ }^{1}$ Meanwhile, Trucost (2013) made the provocative claim that most industries produce such a large quantity of environmental toxins that were the firms to be fined according to law, they would no longer be making a profit. Damage caused by firms' environmental practices-including emitting harmful greenhouse gases, polluting local air, and over-using and polluting freshwater-would have cost them $\$ 12$ trillion in 2008 (Jowit, [2010]).

Although regulation can play an important role, it is an incomplete solution; there are already many laws against such practices, but not all firms comply. In fact, environmental law breaking often goes unpunished or the companies involved circumvent heavy fines, paying significantly less than the original penalty. For example, in 2004, the State Department of Environmental Protection files lawsuits against Exxon Mobil Corporation for $\$ 8.9$ billion in damages for the contamination and loss of use of more than 1,500 acres of natural land and waters in northern New Jersey. Exxon, however, skirted the almost nine billion dollar penalty, and after eleven years, settled with New Jersey State for $\$ 250$ million (Weiser [2015]). In 2013, Wal-Mart pleaded guilty to six counts of violating the Clean Water Act through illegal handling and disposal of hazardous materials at its retails stores across the United States, and was made to pay $\$ 81.6$ million (U.S. Department of Justice [2013]). Wal-Mart failed to train its employees on proper hazardous waste disposal, leading to waste placed in city trash bins or poured into local sewer systems.

Since firms are run by managers, an important driver of firm behavior is managerial incentives (e.g., Jensen and Meckling [1976], Porter and Van der Linde [1995], Murphy [1999], and Goergen and Renneboog [2011]). Motivated by these observations, this paper asks a simple question: to what extent does executive compensation push firms into environmental law-breaking in particular and misconduct in general?

It is well established that executive compensation induces managers to influence myriad important firm outcomes, such as risk-taking, innovation, and acquisition and divestitures (e.g., Sanders [2001], Rajgopal and Shevlin [2002], Sanders and Hambrick [2007], and Low [2009]). However, more recently, critics have suggested that such compensation has led to drastically harmful events, such as the recent financial crisis and major oil spills. Indeed, the Financial Crisis Inquiry Commission (2011) claimed that the compensation systems for the "corporate boardroom" regularly incentivized the "big bet" by providing enormous rewards for obtaining financial gains while providing few penalties for avoiding losses, thus contributing to the 2007-2008 financial crisis. Another dramatic example is the environmental disaster by British Petroleum (BP) in 2010. The figure below

\footnotetext{
${ }^{1}$ See http://www.dsm.com/corporate/media/informationcenter-pub/2015/04/2015-04-17-open-letter-from-globalceos-to-world-leaders-urging-concrete-climate-action.html
} 
reports the cumulative award of options and stocks for BP CEOs Lord Browne and Tony Hayward, both of whose careers ended after spectacularly destructive oil spills. In the case of Lord Browne, shares of stocks, and especially shares of options, reached a pinnacle just before the Prudhoe Bay oil spill. Following this disaster, Tony Hayward took over as CEO and began with a large number of options and stock. He would very soon be the executive held responsible after the massive Gulf of Mexico spill, though he did sell a sizable portion of his options just prior to it. We ask ourselves, are these examples merely suggestive or do they inform us of something deeper at work?

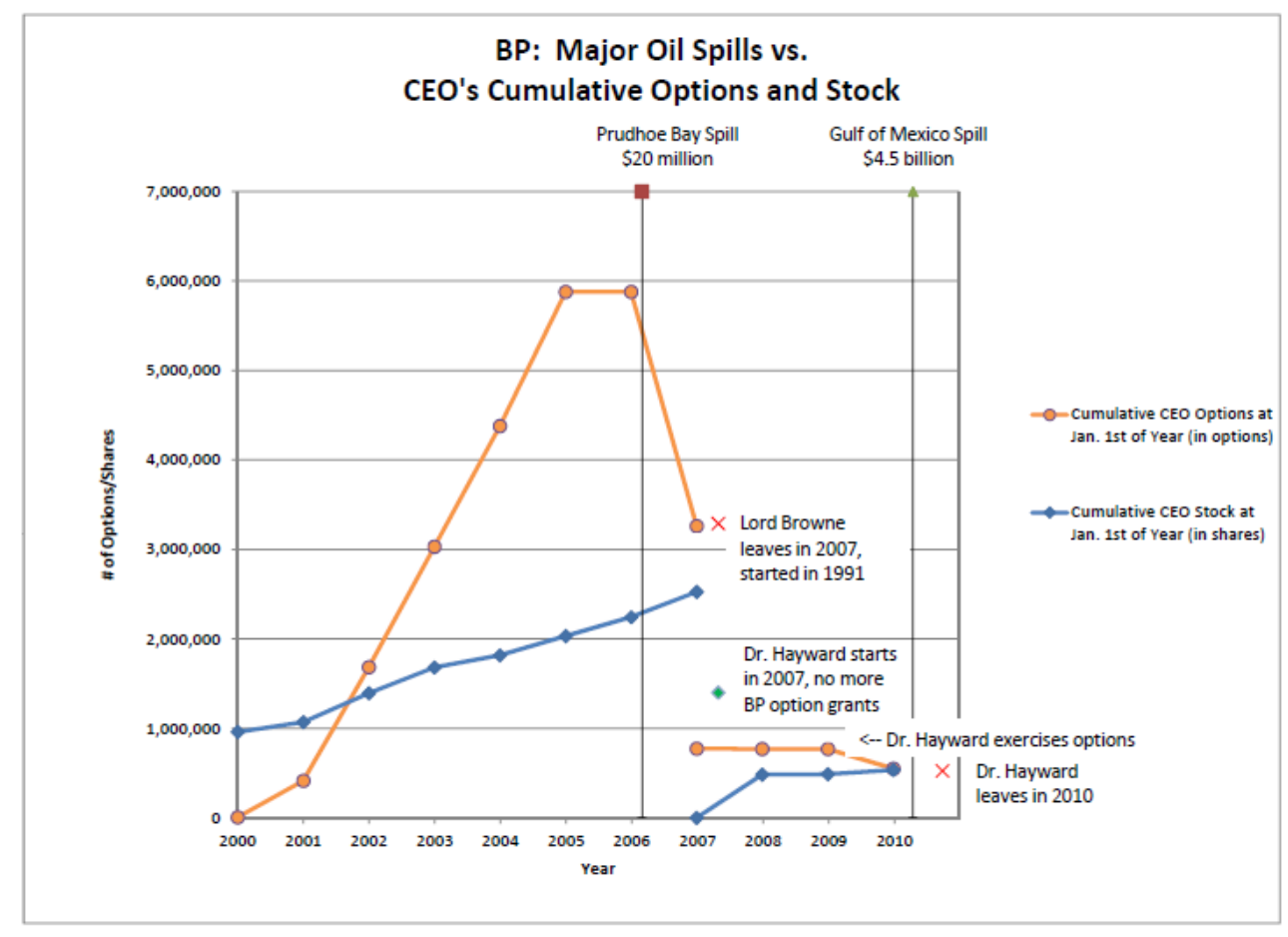

To answer this question we begin by constructing a simple measure that we call the pay index $P$. This index $P$ captures the relative incentives of an executive in terms of upsides and downsides in potential firm performance through equity compensation composition. We then use this index to predict both the magnitude and severity of misconduct. To validate the compensation measure beyond theory, we apply it to the settings of environmental misconduct and financial accounting misconduct. We find that changing a CEO's index $P$ from zero (i.e., $100 \%$ of equity pay in stock) to 1 (i.e., $100 \%$ of equity pay in options) results in a CEO's firm facing $42-65 \%$ increased odds of breaking environmental law. In addition, such change in compensation is linked to nearly a $100 \%$ increase in the magnitude of environmental harm, as measured by total government fines.

Not only is environmental law-breaking bad for the environment, but mishaps can also damage firm value. Klassen and McLaughlin (1996), Konar and Cohen (2001), Karpoff et al. (2005), Capelle-Blancard and Laguna (2010), Flammer (2013), and Krüger (2015) all show that when environmental concerns for a firm are made public, the firm suffers a material loss in market value. In addition to direct losses, such as regulatory penalties and civil litigation, firms might also suffer 
substantial losses due to damaged reputations. Although certain types of incentives can provide positive sustainability outcomes (e.g., see Eccles, Ioannou, and Serafeim [2013], Ferrell, Liang, and Renneboog [2015], and Hong, Li, and Minor [2015]), our findings suggest conventional financial incentives can influence adverse environmental outcomes and may be another important channel for preserving or damaging firm value.

To validate the index $P$ in an entirely different setting, we explore the relationship between compensation structure and the likelihood of suspected accounting misconduct and negative earnings restatements; the findings for this setting are similar to those in the environmental setting. We also find evidence that these effects come at least partially from incentive rather than selection effects. Finally, we explore the consequences of two policies to potentially ameliorate the negative effects of high powered incentives.

We see this paper's contribution as three-fold. First, we construct and validate, a new (to the best of our knowledge) compensation index $P$ that measures propensity for misconduct. Second, we document the effects of executive compensation on the likelihood and magnitude of environmental harm. Third, we provide some policy recommendations to blunt the adverse effect of executive compensation.

\section{Theoretical Considerations}

We begin by constructing our index $P$ and generating several hypotheses. In the online appendix, we formally derive $P$. However, here we simply provide the intuition of the measure and its predictions. We first motivate our theoretical considerations by example.

Misconduct is often born in a probabilistic fashion. That is, a CEO can choose to pursue greater profit at the potential expense of increased harm and cost, leaving any downside to chance. For example, in the case of the BP Prudhoe Bay spill, there was a tradeoff for executives: they could increase profits almost immediately by cutting safety expenditures, but this would increase the potential of an environmental accident. BP decided to accept the risk of this tradeoff, which ultimately resulted in an oil spill. The government fine alone for its Prudhoe Bay spill was $\$ 20$ million, and additional costs, of course, far exceeded this amount. The primary cause of the spill was deemed to be poorly maintained pipes. This allegedly arose from BP's dogmatic adherence to cost-cutting, which was encouraged by the CEO's implementation of cost cutting incentives for top managers. With roughly 250 of BPs top managers, the CEO created an annual "contract" that was based on short-run annual profits of each respective manager's division. ${ }^{2}$ Prosecutors estimated that subsequent lax safety standards saved the firm some $\$ 9.6$ million. ${ }^{3}$ Hence, the firm enjoyed roughly $\$ 10$ million of almost certain profit but faced the potential of an over $\$ 20$ million cost.

The next BP CEO, Tony Hayward, was also committed to a policy of shaving costs: almost

\footnotetext{
${ }^{2}$ These institutional details can be found in the Fortune magazine article available here: http:/ features.blogs.fortune.cnn.com/2011/01/24/bp-an-accident-waiting-to-happen/.

${ }^{3}$ Associated Press via MSNBC News on 11/29/2007. Available at: http://www.msnbc.msn.com/id/22014134/ns/businessoil_and_energy/t/bp-pleads-guilty-alaska-oil-spill/.
} 
immediately upon becoming CEO, Howard emailed associates about the importance of continued cost cutting. Once a CEO decides to risk (more) harmful outcomes - e.g., with safety cost-cuttingin exchange for greater profit, it may be only a matter of months until such a strategy increases the chance of an incident and its magnitude. For example, if pipelines are inspected and maintained monthly, a CEO may decide to save costs by ordering inspections on a six month basis instead, thus increasing the liklihood of malfunction which may result in costly or fatal damage. For a different example in financial accounting, it could be that a CEO incepts direct incentives with frontline managers to encourage aggressive financial accounting practices, leading to an increased chance of accounting misconduct and its magnitude.

For an entirely different setting, consider again the Wal-Mart example in the introduction. Executives can increase at least near-term profits by dumping toxic waste as regular refuse, as both hazardous waste disposal fees and training costs are avoided. In this case, environmental harm is all but certain. However, as in the BP examples, the firm's cost for misconduct occurs at some probability less than one.

More generally, this decision to accept the greater risk of harm for greater profit can be thought of as a CEO choosing between two strategies, one riskier than the other, but with a greater reward. The following chart illustrates these options.

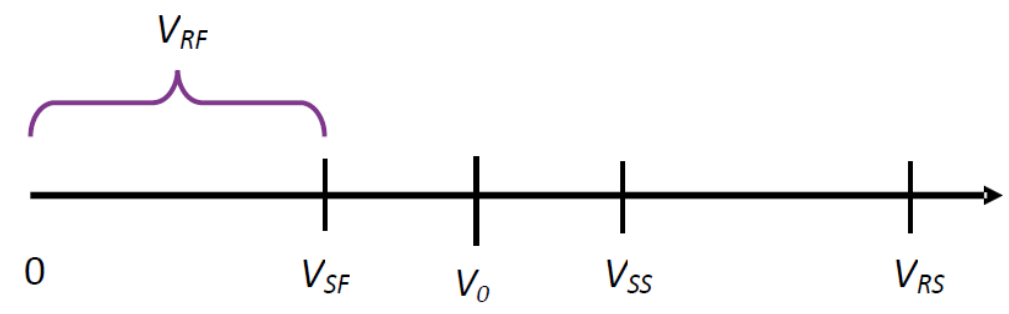

For example, consider a firm that is worth some value $V_{0}$. The CEO can choose a safer strategy that has an upside of successfully growing the firm to value $V_{S S}$ and if the strategy fails, a downside of firm value $V_{S F}$. This strategy can be thought of as the benchmark, or status quo, strategy. Alternatively, the CEO can choose a project with greater upside $V_{R S}$, but some level of downside $V_{R F}$ that is worse than the downside that accompanies the safer strategy.

A CEO will choose one strategy over the another as a function of her compensation incentives. For CEOs of large US public firms, most of their compensation is in the form of equity compensation: company options and stocks. Thus, the nature of equity compensation is expected to be the biggest incentive driver of CEO decision making. In general, when a CEO is paid in the form of company stock, they become the residual claimant of her company - being equally affected by both increases and decreases in firm value - and will thus weight both potential losses and gains in deciding their course of action (Murphy [1999] and Zhang et al. [2008]). In contrast, when a CEO is paid in the form of company stock options, she will only enjoy a financial return if the firm grows in value and will experience the same financial return if the firm does not change in value or loses $50 \%$ of 
value. ${ }^{4}$ Therefore, a CEO will choose one strategy over another as a function of the relative "pull" of options (i.e., reach for high returns without regards to downside) versus the "pull" of stocks (i.e., balance the potential gains and losses).

In light of above, it may seem that responsible firms should only pay their CEOs in the form of stock. However, options can be a lower cost form of compensation because the firm only has to pay the CEO if the firm grows in value, where with stock, the CEO is being given some value of the company whether the firms grows or even shrinks in value. Thus, the firm also has a tradeoff in how much stock versus options to offer the CEO. In the online appendix, we derive the optimal mix of stocks and options that the firm will choose. We derive the following compensation pay ratio, we call index $P$, to measure this optimal mix:

$$
P=\frac{O}{O+S}
$$

where $S$ is the expected value of stock paid and $O$ is the expected value of options paid.

The greater the index $P$, the greater the share of equity compensation in options-which means the greater the net pull to take on the larger risk of potential downside and thus harm. Notice that if we only measure the level of options, this would not be sufficient to determine the incentives for misconduct because we also need to know the degree of offsetting force from the level of stocks. This index $P$ captures these net forces in a simple, single metric.

Now given some index $P$, as shown in the online appendix, a CEO will choose some threshold of downside value $V^{*}$ such that any potential strategy that has a lower (i.e., worse) downside than $V^{*}$ would never be chosen, and any strategy with higher downside (i.e., better or less harmful) than $V^{*}$ it would be chosen. The greater the index $P$, the greater the pull to take on a strategy with a larger downside, since the CEO internalizes less of the downside. This means that on average those CEOs with greater $P$ will choose a lower threshold $V^{*}$. Therefore, whenever a CEO chooses a course of action that fails, there is greater harm and cost on average. This provides our first hypothesis for our environmental setting.

Hypothesis 1: The magnitude of environmental harm is increasing in index $P$.

Similarly, when we study financial accounting misconduct, we should find that the magnitude of misconduct is increasing in $P$. For this setting, the magnitude of misconduct can be measured by the amount of improperly enhanced earnings.

Hypothesis 2: The magnitude of accounting misconduct is increasing in the index $P$.

The other dimension of misconduct is its likelihood of a harmful outcome. This can also be determined once we have fixed the CEO's standard of downside $V^{*}$. The CEO will face a variety of alternatives to the benchmark strategy, with downsides ranging from 0 to $V_{S F}$. The lower the downside standard $V^{*}$, the more often a CEO will choose a strategy with a greater downside than the benchmark one. This means that on average this CEO will be engaging in more strategies that

\footnotetext{
${ }^{4}$ This assumes the options are issued "at the money." Many times options will be issued at an even higher strike prices than the current stock price, which means that unless the firm grows enough in value there is still no financial return to the CEO. That is, the CEO earns zero financial return at low and negative changes in firm value.
} 
cause harm when they fail. CEOs with increased $P$ will be choosing lower standard $V^{*}$. Thus, the odds of a harmful event are increasing in $P$. This generates our next prediction:

Hypothesis 3: The odds of a harmful environmental event are increasing in $P$.

For the setting of financial accounting, the logic is the same: those with greater incentive through a larger $P$ to enhance profits at the expense of greater downside, will more often choose the potentially harmful route, which means we more often see harmful events.

Hypothesis 4: The odds of accounting misconduct are increasing in $P$.

Finally, we consider some possible policies to alleviate the adverse consequences of increased $P$. A natural first policy to consider adding a "stick" or penalty against the CEO when a harmful event happens. This is in part what a law like Sarbanes-Oxley seeks to achieve: the executives become more personally accountable for negative events. However, in our setting, adding an executive penalty does not affect the equilibrium risk-taking. This is because if the executive now faces a larger penalty for a harmful outcome, the firm can simply offset the larger potential executive penalty with a larger $P$, thus retaining the firm's original preferred level of risk-taking. As long as the executive penalty is not too severe, there should be little to no effect on the odds of taking on a strategy with a potentially more harmful downside.

Hypothesis 5: Adding executive penalties for harmful outcomes does not increase the odds of harmful events.

An alternative policy is to make the firm's provision of options more costly. One way to do this would be through reducing the tax benefits of providing options. For example, this is part of what the accounting rule FAS123R achieved. With the firm trading off the relative costs of providing options and stocks to its executives, on average, it should provide relatively fewer options. This outcome would decrease the likelihood of harmful events.

Hypothesis 6: Making options relatively more expensive to provide reduces the odds of harmful events.

Now we take these predictions to the data.

\section{Empirical Analysis}

\subsection{Executive Compensation and Environmental Harm}

We use the setting of environmental harm as our primary test of executive compensation and misconduct. This environment has several desirable features for this study. First, at least for larger US firms, environmental failures are relatively easy to capture by means of public disclosure - both in terms of incidence and magnitude. Second, for most large US companies, we can identify compensation data on the firm's CEO. Third, environmental incidents, in aggregate, are economically significant.

Our particular environmental dataset, CEPD, was compiled by the IRRC. For the period 1996 through 2006, the IRRC aggregated breaches of environmental law for each physical location of a 
firm's operation up to the company level. In total, this included the (approximately) top 1,500 US public firms in the United States. MSCI acquired the CEPD dataset and has not increased the observations beyond 2006. Violations include the breaking of a myriad of environmental laws: Atomic Energy Act, Clean Air Act, Clean Water Act, Endangered Species Act, Federal Insecticide, Fungicide and Rodenticide Act, Mining Safety and Health Act, Resource Conservation and Recovery Act, Safe Drinking Water Act, and Toxic Substances Control Act. The CEPD dataset includes both the incidences of violation for each of these environmental acts, as well as the total governmentimposed fines. A particular incident may induce several violations of environmental law-both multiple violations of a single act, as well as multiple violations of various acts.

We consider the magnitude of the total government fine (i.e., the total fines across all counts of environmental lawbreaking for an incident) as a proxy for the severity of harm. Government fines are typically only a fraction of the overall cost of an event. For a dramatic example, BP's Prudhoe Bay spill induced a $\$ 20$ million government fine for violating environmental laws. However, BP also had to pay $\$ 25$ million in civil costs, $\$ 60$ million for instituting a new government-mandated safety program, and some $\$ 500$ million of construction costs, bringing the final bill to at least $\$ 605$ million. ${ }^{5}$ Hence, for this particular case, the $\$ 20$ million reported in our CEPD dataset represents roughly $3.3 \%$ of the total cost.

In total, the CEPD includes both large and small violations. The mean government fine for our data is approximately $\$ 223,000$. Based on the Prudhoe example above, this would amount to $\$ 6.8$ million in total average expenses. ${ }^{6}$ Only the largest of these failures would be considered an environmental disaster. However, smaller violations can indicate an increased chance of generating a larger and more harmful - a "tip of the iceberg" signal. If we only considered the most extreme events, there would be too few for identification. Instead, in our analysis, in addition to considering any lawbreaking events, we also separately analyze small and large incidences.

We merge the CEPD dataset with COMPUSTAT and Execucomp data to identify firm financials and CEO compensation. Firm financial controls include firm leverage, defined as total debt to total assets, firm market value, and Tobin's Q. For CEO compensation, we obtain the annual value of options and stock awards. These two values are then used to calculate the index $P$ as identified from our theory section in equation (6). Finally, as controls, we include a CEO's total annual compensation and the percent of total compensation paid in the form of equity compensation. Thus, we are estimating the relationship of the composition of equity compensation conditional on both the total level of compensation and the fraction of pay devoted to equity compensation.

Although we control for firm invariant environmental factors through firm fixed effects, this does not control for any time-varying environmental effects. To address this, we merge data from KLD analytics on the environmental-performance ratings of firms. Chatterji et al. (2009) find that environmental-performance ratings, as measured by KLD analytics, are important in explaining

\footnotetext{
${ }^{5}$ Figures are reported by the Associated Press in The Guardian 5/4/2011, available here: http://www.guardian.co.uk/environment/2011/may/04/bp-25m-north-slope-oil-spill

${ }^{6}$ Unfortunately, there are very few events with sufficient data on total expenses incurred for the incident, which is why we focus on the government fines.
} 
next year's firm environmental failures, as measured by the CEPD database. Thus, we will be testing whether, conditional on observable environmental outcomes, compensation structure further explains environmental events. More recently, Servaes and Tamayo (2013) also find KLD analytics an important source of CSR data, explaining firm value.

Summary statistics for our primary variables are reported in Table 1. On average, firms experience an event (i.e., a breach of at least one environmental law in a given year) about $15 \%$ of the time, or about every six years. Firms are also large - averaging over $\$ 11$ billion in market capitalization. The average CEO receives about $\$ 6$ million per annum in total compensation, and about $75 \%$ of equity compensation is in the form of options (i.e., index $P$ ). We find that the correlation of total equity compensation and total compensation has a correlation of .96, which means most all of the variation in total compensation comes from the amount of equity compensation, which is the focus of our study.

\subsubsection{Results: Environmental Events}

Our primary regression model for analyzing incident rates is a panel logit model with firm fixed effects. Specifically, we use

$$
\operatorname{Pr}\left(\text { Event }_{i t}=1\right)=\frac{1}{1+e^{-Q_{i t}}}
$$

where Event $t_{i}$ equals 1 when firm $i$ has broken the law in year $t$.

$$
Q_{i t}=\alpha_{i}+\beta \frac{O_{i, t-1}}{O_{i, t-1}+S_{i, t-1}}+\mathbf{X}_{i t} \boldsymbol{\delta}
$$

where $\alpha_{i}$ is a fixed effect for firm $i$, and $\mathbf{X}_{i t}$ is a matrix of control variables that include year fixed effects and financial and environmental performance controls outlined in the previous section. The regressor $\frac{O_{i, t-1}}{O_{i, t-1}+S_{i, t-1}}$ is the index $P$ from our theory model and is calculated as the ratio of the total value of CEO option awards to the total value of CEO option and stock awards at time $t-1$ for firm $i{ }^{7}$ Hence, the coefficient estimate $\widehat{\beta}$ of $\beta$ is our primary estimate of interest. Hypothesis 2 predicts that $\beta>0$. Although estimating fixed effects is possible in the panel logit setting, to do so, we must drop observations of firms that never have an event or firms that have an event ever year. Of the 1, 459 firms in our sample, 3.2\% have an event every year and $74.5 \%$ never experience an event during our time series. By firm, the mean number of events across the entire 11-year time series is 1.3. Conditional on a firm having at least one event, the mean number of events is 3.5 across the 11 years.

In addition to this primary specification, we estimate a linear panel model with firm fixed effects. Although this model must assume the probability of an event is linear in its terms, it allows us to

\footnotetext{
${ }^{7}$ Based on personal conversations with officials at the Environmental Protection Agency and a human resource consultantcy, it appears that with this $t-1$ specification, a CEO typically knows her compensation structure 6-24 months before an event occurs in our $C E P D$ data.
} 
consider those firms that never or always have an event in our sample. We specify this model thus:

$$
\text { Event }_{i t}=\alpha_{i}+\beta \frac{O_{i, t-1}}{O_{i, t-1}+S_{i, t-1}}+\mathbf{X}_{i t} \boldsymbol{\delta}+e_{i t} .
$$

In our first prediction, we consider the relationship between $P$ and incident rates. We then turn to our second prediction - the relationship between $P$ and the magnitude of events.

\subsubsection{Increased $P$ Results in Increased Odds of an Event}

We report our baseline specification in Table 2. Column (1) reports results controlling for unobserved firm heterogeneity and total CEO compensation. The logit estimate of roughly 0.5 can be converted to an odds ratio format, ${ }^{8}$ yielding $e^{0.5}=1.6487$. This means that if a CEO goes from receiving all equity compensation in stock (i.e., $P=0$ ) to receiving all equity compensation in options (i.e., $P=1$ ), her firm will have $64.87 \%$ increased odds of facing an environmental incident the next year. Adding all of the other controls does little to change the relative magnitude and significance of the coefficient of interest, as shown in columns (2)-(4) .

We next consider our linear panel model with firm fixed effects. Table 3 reports coefficient estimates for this specification. Note that the observations for column (1) are 5, 108 compared with 1,750 for column (1) in Table 2; this is due to the inclusion of all firms (i.e., adding those firms that never and always face an event in a given year). As seen in column (1), coefficient estimates suggest that the probability of an environmental incident increases by approximately $5 \%$. Recall from Table 1 that the baseline chance of an event is $15 \%$, which means that a CEO going from equity compensation structure $P=0$ to $P=1$ results in a $33 \%$ increased chance of an event. We can convert our linear model coefficient estimate to odds in order to compare these estimates with our results found in Table 2. In particular, a baseline probability of $15 \%$ means that the odds of an event are $\frac{15 \%}{85 \%}=0.17647$. Adding another $5 \%$ chance results in an event odds of $\frac{20 \%}{80 \%}=0.25$. This means the impact of a CEO going to $P=1$ from $P=0$ results in an odds ratio of $\frac{0.25}{0.17647}=1$. 416 7. In other words, our linear specification estimates that a CEO going from equity compensation consisting of all stock to all options increases the odds of an event by $41.67 \%$, versus our panel logit model, which predicts increased odds of $64.87 \%$. Both of these estimates are substantial in magnitude and both models report coefficient estimates that are significant at the $5 \%$ level.

Thus far, we have been using firm fixed effects to control for unobserved firm heterogeneity. Recent financial economic research suggests that not doing so can produce spurious results and incorrect inferences (see Gormley and Matsa (2014)) . Nonetheless, if fixed effects are not called for, we are, of course, using a less efficient estimator, possibly failing to identify other important effects. We run a Hausman test to determine if a linear random effects panel model would be appropriate given that a linear fixed effect panel model is correct. Since we are using clustered standard errors, it is important not to use the conventional Hausman test, which assumes $\alpha_{i}$ and $e_{i t}$ are i.i.d.- - but this is violated if clustered standard errors are appropriate for within-firm serial

\footnotetext{
${ }^{8}$ Recall that the odds of an event is calculated as $\frac{\operatorname{Pr}[\text { Event }=1]}{\operatorname{Pr}[\text { Event }=0]}$. The odds ratio is the ratio of two odds.
} 
correlation. Instead we turn to the method of Wooldridge (2002) to accommodate our setting. Results from this test report a Sargan-Hansen statistic of 113.50, which yields a p-value $=0.0000$. Hence, we can strongly reject the efficacy of using a random effects model for our empirical setting.

To consider the importance of larger versus small events, we return to our logit fixed effects panel model and recode events as either bottom-quartile or top-quartile magnitude events. Magnitude is again the total government fines imposed for an incident. Table 4 reports these results. Column (1) contains the same specification reported in column (4) of Table 2, which contains all controls. Column (2) shows us that if we define events as only those in the smallest quartile magnitude-wise, the point estimate is statistically indistinguishable from zero. The top quartile, however, has a coefficient estimate on $P$ that is roughly twice that if we include all events: 1.13 vs. 0.53 . This estimate from column (3) suggests that a CEO's firm with an index $P=1$ will have almost triple the odds of breaking environmental law in the next year compared to a CEO's firm with an index of $P=0$.

We also conduct the same exercise with our linear fixed effect model so that we can include all observations. Table 5 reports these results, which are similar to those in Table 4: the top-quartile events are significantly related to $P$, and the bottom ones are not. In sum, these findings suggest that in terms of incident rate, $\mathrm{CEO}$ compensation structure, as measured by $P$, is especially related to high-stakes events.

\subsubsection{Robustness Tests}

If CEO compensation influences environmental harm and disasters, it should not be the case that this year's odds of an event influence next year's compensation structure $P$. In order to this, we rerun the specifications in Table 2 with the modification that we measure $P$ the year after rather than the year before an event. As reported in Table 6, none of the specifications are significant.

Another natural question is to what extent compensation structure $P$ is simply a proxy for other important compensation variables. First, it could be that the total option awards currently held by a CEO are what really matters in determining incident rates; last year's option award is simply a proxy for this larger value. Similarly, it could also be that the current total value of stock held by the CEO is what really determines incident rates and $P$ somehow proxies for this. We explore these possibilities by rerunning the specification from Table 4 in column (3) (i.e., the specification with all of our controls) and then adding controls for a CEO's value of total stock and option awards currently held through the previous year, each logged. ${ }^{9}$ We report these results in Table 7. For comparison purposes, column (1) replicates the results from column (3) in Table 4: our baseline regression with all controls. Column (2) then adds lagged values for the log of total stocks and options owned by the CEO. Surprisingly, neither regressor can help predict the odds of an environmental event. Meanwhile, the coefficient $P$ changes little in estimate or significance when these additional controls are added.

\footnotetext{
${ }^{9}$ Specifically, we calculate the $\log$ of the current total options and stock holdings as each $\ln (1+$ Value $)$, where Value is the value given by Execucomp for each of the total holding values. Execucomp includes zero values.
} 
Another potentially important measure of executive compensation is the CEO's Delta of her options portfolio. Some argue that Delta should increase risk-taking, whereas others argue that it should decrease risk-taking. This ambiguity arises both in the theory and empirical literature (see Coles et al. (2006) and cites therein). For this paper, Delta is the dollar change in CEO wealth as fa unction of a $1 \%$ change in stock price. We calculate the CEO's Delta for each executive in our sample using the same method as in Guay (1999) and Core and Guay (2002). The results of adding this measure of Delta as a regressor are reported in column (3). The coefficient on Delta is not statistically different from $0 .{ }^{10}$ The coefficient on the index $P$ is now slightly greater and even more significant at the $1 \%$ level.

A final common measure of the nature of equity compensation, is Vega. This measures how much of an increase in wealth a $\mathrm{CEO}$ receives with a $1 \%$ increase in her company's stock volatility. We calculate this measure as in Guay (1999) and Core and Guay (2002). All things equal, this measure should be positively correlated with managerial risk-taking (see Coles et al. (2006)). However, it should be positively correlated with managerial risk-taking that increases the company's stock volatility. Column (4) reports that our coefficient on Vega is positive but no different statistically from zero. This suggests that while Vega tends to do well in capturing traditional measures of risktaking, it does not seem to capture increase risk of environmental harm. Meanwhile, the coefficient on our compensation index $P$ becomes greater in magnitude and significance than when we do not control for Vega.

In total, it seems that our compensation index $P$ is not simply a noisy proxy for measuring other important executive-compensation measures. In fact, for our setting of the risk of environmental harm, it seems to do a better job than the extant measures. In one sense this is not surprising, as an increased risk of environmental harm, especially the kind that results in spectacular disasters, could be considered more of an "off balance sheet" risk. The conventional measures of managerial risk-taking - firm leverage, reduced cash surplus, R\&D investment, reduced capital purchases, and more-focused lines of business and acquisitions - are all forms of risk-taking easily observable by the financial market and thus embedded in a company's stock return and volatility. In contrast, managerial choices, such as shirking on oil-pipe inspections or choosing not to install automatic shutoff valves on oil platforms, are much more difficult for the market to identify and price into a company's stock. Perhaps the index $P$ can help on that dimension in predicting such risks.

\subsubsection{Increased $P$ Results in Increased magnitude of harm}

For testing our second prediction, we use a similar specification to our linear panel model in the previous section. However, we change our dependent variable from an event indicator to the log of total government fines. We utilize the following model:

\footnotetext{
${ }^{10}$ Similar result are obtained by including separate measures for the executive's stock and option deltas rather than using the aggregate total.
} 


$$
\ln \left(1+\text { fine }_{i t}=\alpha_{i}+\beta \frac{O_{i, t-1}}{O_{i, t-1}+S_{i, t-1}}+\mathbf{X}_{i t} \boldsymbol{\delta}+e_{i t},\right.
$$

where fine is the total government fine assessed for the incident and all of the other regressors are as they were in equation (2). Of course, since Prediction 2 is a conditional prediction, we now only have observations for those firm-years that record an environmental incident. Our main coefficient of interest is again $\beta$.

Table 8 reports the results for similar specifications to those in Table 2. The first three specifications yield a significant coefficient on $P$ at the $5 \%$ level. The final specification with all controls yields significance at the $10 \%$ level. Since these are semi-elasticities, the coefficient estimates suggest that, roughly speaking, a CEO going from $P=0$ to $P=1$, conditional on experiencing an event, will witness greater total event costs of $84 \%$ to $100 \%$.

Since we are using a linear panel FE model, we again need to ask if it is the appropriate model vis-a-vis a random effects model. Conducting a Hausman test, as we did in our previous section, we find a Sargan-Hansen statistic of $39.948 \mathrm{p}$-value $=0.0008$, which causes us to strongly reject the null hypothesis that the random effects model is appropriate given that the fixed effects model is appropriate.

We again consider the comparison of the large and small events. Unfortunately, we now have a significantly reduced sample size compared to the previous section; thus, we now simply partition fines into below median and above median fines. We use all of the controls used for the results in column (4) of Table 8 for Table 9. For comparison purposes, column (1) in Table 9 replicates the results in Column (4) of Table 8. We find that using the sample of large (i.e., above median) fines creates an estimate of the coefficient on $P$ significant at the $5 \%$ level compared with a $10 \%$ significance level when using the sample of all fines. Further, the estimate using only larger fines is over $50 \%$ greater in magnitude compared with the full sample that includes small fines. Meanwhile, a sample of only small fines does not yield a significant estimate of the coefficient on $P$.

We also rerun the specification from column (4) in Table 8 with the addition of the natural log of total company stock, options, Delta, and Vega. Again, none of these control variables are significant, and they do not materially change the results. Similarly, the current magnitude of an event does not predict next year's compensation structure $P$.

\subsubsection{Selection vs. Incentives}

Although it seems that higher $P$ results in greater rates of and magnitudes of misconduct, it is not clear if this is because of selection or incentives. It could be that firms that want to take on greater risk of harm, attract those CEOs more willing to do so by offering a higher $P$ (as opposed to the greater $P$ incentivizing greater risk of harm). In an attempt to disentangle these two possibilities, we conduct the same exercise as in the last two subsections, but now at the CEO-firm level. That is, we use a fixed effect for each CEO-firm pair, whereas before that fixed effect was at the firm level. Thus, we will only be able to identify any effect of $P$ on environmental law-breaking by 
the variation of $P$ while a particular CEO is at one particular firm. Although this approach will potentially remove significant variation from the analysis, it allows us to better identify the incentive versus selection effect. If there is no effect of $P$ at the CEO-firm level, then we cannot rule out that the effects of $P$ come through selection as opposed to incentives.

In Table 10, we report the results of both a logit and linear fixed effects model for the CEOfirm pair level. Now, the high-magnitude (i.e., top-quartile) events are significant (at the $5 \%$ level). Thus, identification is coming from the larger-stakes events, which parallels our earlier findings when analyzing the data at the firm rather than CEO-firm level. In terms of magnitude of effect, the coefficient estimates at the CEO-firm level (when we include all events of all magnitudes) are about half of the magnitude of those at the firm level. However, the top-quartile estimates are similar for both levels of analysis.

In terms of $P^{\prime}$ s effect on the magnitude of an event, as reported in Table 11, the values are similar. In terms of significance, the CEO-firm level has lower significance for its estimates, which is not a surprise since we are now only identifying these differences from pay variation of a particular CEO while at a single firm. The final column with all controls has a p-value just short of $10 \%$, whereas all of the other specifications carry p-values of less than $10 \%$.

In sum, it seems that a substantial portion of the effect identified earlier at the firm level is also occurring at the CEO-firm level, at least for the high-magnitude events. This suggests that CEO compensation effects on environmental law-breaking are occurring largely through incentive provision (and not simply selection).

Despite all of the above findings, it is possible the index $P$ only predicts the incident rate and magnitude of events for environmental harm and not other settings. To further explore this possibility, we now analyze the index $P$ in a different setting and different time period: financial accounting misconduct.

\subsection{Executive Compensation and Financial Accounting Misconduct}

Financial accounting represents another setting in which, similar to environmental harm, getting caught for breaking accounting law can be viewed as a failed strategy that had a greater downside. Firms can choose to be more aggressive in their accounting practices, magnifying their firm's financial downside. In our setting, an event is an earnings restatement that results in an SEC investigation. This means that we are really measuring the likelihood of breaking the law; to the extent that being investigated by the SEC for suspicious financial accounting is correlated with greater risk-taking, we can conceptualize an SEC investigation as a signal of higher risk-taking.

The reason that we proceed with this section of analysis is many-layered. First, some studies have shown that options pay is related to accounting misconduct (e.g., see Burns and Kedia [2006] and Armstrong, Jagolinzer, and Larcker [2010], and cites therein). Since we are using a new measure of equity pay (i.e., $P$ ), we want to examine if its use replicates past results obtained using other measures. Second, restatements with SEC investigations are rare events: these carry less than a $0.5 \%$ annual incident rate in our dataset, which allows for testing our predictions in an entirely 
different setting from our environmental law-breaking one. Finally, at the end of 2005, it became more costly to provide options due to FAS 123R. ${ }^{11}$ Our accounting data cover the period 2000 through 2011; hence, we can consider any differential effects of options before and after this policy change, which is not possible with our environmental data since the database was discontinued after 2006. We can also consider any time-trend differences between another major policy change (which could affect financial accounting conduct): Sarbanes Oxley. Instead of directly shifting the cost of providing options, as did FAS 123R, this policy essentially increased the penalty an executive faced if he presided over a financial accounting incident. With these policy changes, we can test Hypotheses 5 and 6.

Our analysis proceeds just as before. However, our dependent variables are now different. Specifically, we obtain them from Audit Analytics, which reports accounting restatements and whether or not these result in an investigation by the SEC. Restatements can be due to simple, benign clerical errors or more serious actions, such as earnings manipulation. The most suspicious of restatements are the ones, presumably, investigated by the SEC. Audit Analytics also reports the net change in earnings of a restatement.

For this section, we employ a random effects model instead of a fixed effects model. For our linear model, we again conduct a Hausman test. We find in this setting of financial accounting risk-taking, that if a fixed effects estimate model is appropriate, we cannot reject that a random effects model is inappropriate ( $\mathrm{p}$ value of 0.53 ). However, since this then means the Random Effects model is the more efficient estimator, we turn to that model. For consistency, we also use a random effects model for the logit panel. In addition, if we used a fixed effect logit panel model, due to the rare event nature of this sample, we would only be following 50 firms - since the fixed effect model must drop all firms that never have an event.

Table 12 reports our logit panel specifications. Including all controls, as reported in column (3), the coefficient of 1.53 implies a CEO going from receiving all equity compensation in stock to all in options (i.e., $P=0$ to $P=1$ ) will oversee a firm in the following year with some $362 \%$ increased odds of a financial accounting investigation. This coefficient estimate on $P$ is significant at the $5 \%$ level in column (3) and at the $1 \%$ level in the other columns.

Table 13 reports the same specifications as in Table 12 but for a linear panel model. All specifications show the coefficient estimates on $P$ to be significant at the $1 \%$ level and close to an average value of $0.4 \%$, which amounts to an $80 \%$ increase in the likelihood of a financial accounting event. Since incident rates are less than $1 \%$, the increase in odds, as indicated by the odds ratio, is similar to an increase in probability. Converting the $80 \%$ increase in chance to an odds ratio yields 1.81, which implies an $81 \%$ increased odds of an event. Thus, in contrast to our environmental law-breaking setting, the linear estimator and logit estimator imply sharply different increases in odds. When estimating low-probability events, the shape of the tail of the statistical distribution clearly matters.

As mentioned, a nice feature of studying this accounting data, in addition to having a larger

\footnotetext{
${ }^{11}$ See Hayes et al. (2012) for a summary of this rule as it pertains to options accounting.
} 
sample, is that our time series passes through two significant accounting policy changes. We had the passage of both the Sarbanes-Oxley Act (2002) and FAS 123R (2005). The former act essentially created a larger expected penalty for CEOs involved in accounting misconduct. Our Hypothesis 5 predicts Sarbanes-Oxley will have no effect on risk-taking in equilibrium and thus will not be associated with the incidence of restatements investigated by the SEC.

The FAS 123R policy change, in contrast, essentially made it more expensive for a firm to award options. Hypothesis 6 predicts that a rule change like FAS123R should lower misconduct incident rates

We consider these two policy changes with a simple, non-parametric time specification. Specifically, we add an indicator variable that takes on the value 1 for all years that the new policy is effective, which begins in 2002 for the Sarbanes-Oxley Act and 2006 for FAS 123R. To limit collinearity with our year fixed-effects, we create year fixed-effects from 2004 onward. We report these results in Table 14. Columns (1) and (3) do not include year fixed effects and columns (2) and (4) do. Coefficient estimates on $P$ are similar to those derived before 3 adding such policy controls and are significant at the 5\% (1\%) level for the logit (linear) panel. It appears Sarbanes-Oxley had no effect on alleged financial accounting misconduct, at least in terms of SEC investigations. Meanwhile, FAS 123R caused a significant drop in accounting incident rates across all specifications.

We now consider the magnitude of accounting restatements that are investigated by the SEC. Accounting restatements can result in a positive or negative change in earnings. If we restrict ourselves to those restatements that also have an SEC investigation, we have a mere 47 observations with our specifications and not enough power to identify a relationship between CEO compensation and magnitude. Further, of these 47 observations, 22 have a net zero value in earnings restatement, leaving only 25 observations to identify the magnitude of any possible effect.

However, we can more loosely define our event as a negative earnings restatement, rather than one that also results in an SEC investigation. Doing so increases our observations to 283. In contrast to our environmental incident data, accounting restatements are quite rare even for firms that experience one. In fact, for our 12-year sample, for firms that face a restatement, $72.4 \%$ never experience an additional restatement. If we only consider negative earnings restatements, then $82.1 \%$ of firms only experience one such event. Thus, when considering the conditional magnitude of an event, our sample is similar to a cross section. Consequently, we implement an OLS model to measure the relationship of firm compensation and earnings restatement magnitude. We also add industry controls at the NAICS code two-digit level.

We do find a relationship between compensation structure $P$ and the magnitude of negative earnings restatements. Table 15 reports these results. Since these are semi-elasticities, the magnitudes suggest that a CEO going from $P=0$ to $P=1$ will oversee a roughly $49 \%$ to $65 \%$ increase in the magnitude of a negative earnings restatement, conditional on facing such a restatement. 


\section{Conclusion}

We explored how executive compensation affects misconduct. To do so we constructed an index of compensation called $P$, where increased $P$ predicts a greater chance and magnitude of misconduct. We tested these predictions in the setting of breaking environmental and accounting law. We found that changing a CEO's compensation from $100 \%$ stock to $100 \%$ options (i.e., $P=0$ to $P=1$ ) resulted in a $60 \%$ increased odds of environmental harm and close to a doubling of the magnitude of harm. Similarly, for the same change in equity compensation, we found over $80 \%$ increased odds that the firm has an accounting restatement that is investigated by the SEC. We also found that the magnitude of negative earnings restatements increased by over $50 \%$. We also found that the effect of $P$ seems to be coming from an incentive effect and not simply a selection effect.

As far as policy, our results suggest that increasing the regulatory stick against top management for failed risky-project outcomes does not change the incident rate nor the magnitude of loss. Intuitively, making the stick larger does not change the firm's level of desired downside exposure: thus, the firm simply changes $P$ to still induce the same level of exposure as it had before the regulatory change. In contrast, making it more costly to provide a carrot (i.e., increasing the relative cost of providing options) can reduce a firm's choice of potential harm. We found evidence that a rule change of adding a larger executive penalty - Sarbanes-Oxley - did not affect incident rates, whereas a rule change making the higher powered incentives more costly to the firm-FAS $123 \mathrm{R}$ - successfully reduced incident rates.

In terms of managerial implications, we have explored a potential unintended consequence of higher powered incentives, as captured by $P$ : It is well established that high powered incentives can increase positive firm outcomes, but it seems that they can also increase misconduct. Thus, induced increased productivity must be weighed against potential harm (e.g., see Gino and Ariely [2012] and Housman and Minor [2015]). This can be accomplished by simply offering less high powered incentives than would have been offered if not having considered their effects on misconduct. However, firms can also provide some opposing incentives to blunt the adverse effects of financial incentives. For example, there is some evidence that adding incentives for positive sustainability outcomes are effectual (e.g., see Eccles, Ioannou, and Serafeim [2013] and Hong, Li, and Minor [2015]). Nonetheless, not yet explored is how to match these different types of incentives; research that considers the right mix of financial and sustainability incentives could prove promising. That is, exploring executive compensation more holistically-in terms of seeking profit, limiting misconduct, and enhancing sustainability-could provide important new insights. We hope to see such a multi-dimensional approach in future research. 


\section{References}

[1] Armstrong, C. S., Jagolinzer, A. D., \& Larcker, D. F. (2010). Chief executive officer equity incentives and accounting irregularities. Journal of Accounting Research, 48(2), 225-271.

[2] Burns, N., \& Kedia, S. (2006). The impact of performance-based compensation on misreporting. Journal of Financial Economics, 79(1), 35-67.

[3] Chatterji, A. K., Levine, D. I., \& Toffel, M. W. (2009). How well do social ratings actually measure corporate social responsibility? Journal of Economics \& Management Strategy, 18(1), 125-169.

[4] Capelle-Blancard, G., \& Laguna, M. A. (2010). How does the stock market respond to chemical disasters? Journal of Environmental Economics and Management, 59(2), 192-205.

[5] Coles, J. L., Daniel, N. D., \& Naveen, L. (2006). Managerial incentives and risk-taking. Journal of Financial Economics, 79(2), 431-468.

[6] Core, J., \& Guay, W. (2002). The use of equity grants to manage optimal equity incentive levels. Journal of accounting and economics, 28(2), 151-184.

[7] Dowell, G., Hart, S., \& Yeung, B. (2000). Do corporate global environmental standards create or destroy market value?. Management science, 46(8), 1059-1074.

[8] Eccles, R. G., Ioannou, I., Li, S. X., \& Serafeim, G. (2013). Pay for Environmental Performance: The Effect of Incentive Provision on Carbon Emissions. Working paper Harvard Business School.

[9] Edmans, A., \& Liu, Q. (2011). Inside debt. Review of Finance, 15(1), 75-102.

[10] Environmental Protection Agency, (2011). The Benefits and Costs of the Clean Air Act from 1990 to 2020. Available online at http://www.epa.gov/cleanairactbenefits/feb11/fullreport_rev_a.pdf. Accessed on 7-1714.

[11] Ferrell, A., Liang, H., \& Renneboog, L. (2015). Socially Responsible Firms. Journal of Financial Economics, forthcoming.

[12] Flammer, C. (2013). Corporate social responsibility and shareholder reaction: The environmental awareness of investors. Academy of Management Journal, 56(3), 758-781.

[13] Gino, F., \& Ariely, D. (2012). The dark side of creativity: original thinkers can be more dishonest. Journal of Personality and Social Psychology, 102(3), 445.

[14] Goergen, M., \& Renneboog, L. (2011). Managerial compensation. Journal of Corporate Finance, $17(4), 1068-1077$. 
[15] Gormley, T. A., \& Matsa, D. A. (2014). Common errors: How to (and not to) control for unobserved heterogeneity. Review of Financial Studies, 27(2), 617-661.

[16] Guay, W. R. (1999). The sensitivity of CEO wealth to equity risk: an analysis of the magnitude and determinants. Journal of Financial Economics, 53(1), 43-71.

[17] Hayes, R. M., Lemmon, M., \& Qiu, M. (2012). Stock options and managerial incentives for risk-taking: Evidence from FAS 123R. Journal of Financial Economics.

[18] Hong, B., Li, Z. F., \& Minor, D. (2015). Corporate Governance and Executive Compensation for Corporate Social Responsibility. Journal of Business Ethics, forthcoming.

[19] Housman, M., \& Minor, D. (2015). Toxic Workers. Harvard Business School Working Paper 16-057.

[20] Jensen, M. C., \& Meckling, W. H. (1976). Theory of the firm: Managerial behavior, agency costs and ownership structure. Journal of financial economics, 3(4), 305-360.

[21] Jowit, J. (2010, February 18). World's top firms cause $\$ 2.2$ tn of environmental damage, report estimates. The Guardian.

[22] Kadan, O., \& Swinkels, J. M. (2008). Stocks or options? Moral hazard, firm viability, and the design of compensation contracts. Review of Financial Studies, 21(1), 451-482.

[23] Karpoff, J. M., Lott Jr, J. R., \& Wehrly, E. W. (2005). The Reputational Penalties for Environmental Violations: Empirical Evidence. Journal of Law and Economics, 48(2), 653-675.

[24] Klassen, R. D., \& McLaughlin, C. P. (1996). The impact of environmental management on firm performance. Management science, 42(8), 1199-1214.

[25] Konar, S., \& Cohen, M. A. (2001). Does the market value environmental performance?. Review of economics and statistics, 83(2), 281-289.

[26] Krüger, P. (2015). Corporate goodness and shareholder wealth. Journal of financial economics, 115(2), 304-329.

[27] Low, A. (2009). Managerial risk-taking behavior and equity-based compensation. Journal of Financial Economics, 92(3), 470-490.

[28] Murphy, K. J. (1999). Executive compensation. Handbook of labor economics, 3, 2485-2563.

[29] Porter, M. E., \& Van der Linde, C. (1995). Toward a new conception of the environmentcompetitiveness relationship.

[30] Rajgopal, S., \& Shevlin, T. (2002). Empirical evidence on the relation between stock option compensation and risk taking. Journal of Accounting and Economics, 33(2), 145-171. 
[31] Sanders, W. G. (2001). Behavioral responses of CEOs to stock ownership and stock option pay. Academy of Management journal, 44(3), 477-492.

[32] Sanders, W. G., \& Hambrick, D. C. (2007). Swinging for the fences: The effects of CEO stock options on company risk taking and performance. Academy of Management Journal, 50(5), 1055-1078.

[33] Servaes, H., \& Tamayo, A. (2013). The impact of corporate social responsibility on firm value: The role of customer awareness. Management Science, 59(5), 1045-1061.

[34] Trucost. (2013, April 1). Natural Capital at Risk: The Top 100 Externalities of Business.

[35] United States. Financial Crisis Inquiry Commission. (2011). Financial crisis inquiry report: final report of the national commission on the causes of the financial and economic crisis in the United States. Government Printing Office.

[36] U.S. Department of Justice. (2013, May 28). Wal-Mart Pleads Guilty to Federal Environmental Crimes, Admits Civil Violations and Will Pay More Than $\$ 81$ Million.

[37] Wooldridge, J.M. (2002). Econometric Analysis of Cross Section and Panel Data. Cambridge, MA: MIT Press. 


\section{Online Appendix}

\subsection{A Model of Executive Compensation and Misconduct}

Our model is most similar in spirit to that of Edmans and Liu (2011) who assume that a firm must incentivize its manager via debt and stock. Instead, we consider the two instruments to be stocks and options. In addition, whereas they explore contract type as a function of the nature of the firm, we have the different task of linking compensation structure to the outcomes of failures, both in terms of frequency and magnitude. To ease exposition, we relegate proofs to the next section of the appendix.

In our setting, the CEO must choose between a riskier project $R$ and a safer project $S$. Let $p$ be the probability project $R(S)$ succeeds with the firm being worth $V_{R S}\left(V_{S S}\right)$, and $1-p$ the chance it fails, providing a firm value of $V_{R F}\left(V_{S F}\right)$. We could have different $p^{\prime}$ s for each project type. Or we can simply redefine firm value to make it equivalent to having the same $p$ for both $R$ and $S$. To simplify exposition, we choose the latter approach. We also assume $V_{R F}$ is a random variable whose realization is only observable by the CEO and is drawn from some commonly known uniform distribution $G$ distributed with support $\left[0, V_{S F}\right]$. If the the greatest downside project $R$ is chosen (i.e., $V_{R F}=0$ ), failure means that the firm is completely destroyed and becomes worth zero. Finally, it is assumed that any firm-level penalty (e.g., regulatory fines) for a failure is incorporated into the value $V_{R F}$ and $V_{S F}$.

For some opportunities, it may be in the best interest of the firm for the CEO to choose a project $R$ over a safer project $S$. For instance, the principal of the firm will want the CEO to choose $R$ iff $p V_{S S}+(1-p) V_{S F} \leq p V_{R S}+(1-p) V_{R F}$, which is equivalent to

$$
0 \leq p\left(V_{R S}-V_{S S}\right)+(1-p)\left(V_{R F}-V_{S F}\right) .
$$

We denote the initial value of the firm as $V_{0}$ and assume the ordering $0 \leq V_{R F} \leq V_{S F}<V_{0}<$ $V_{S S}<V_{R S}$. Thus, the value of the firm after a riskier success is the greatest, but a riskier failure leaves the firm worth the least.

The following diagram summarizes the ending firm value $V_{i j}$, with the project type $i \in\{R$ isky, $S$ afe $\}$ and outcome $j \in\{S$ uccess, Failure $\}$

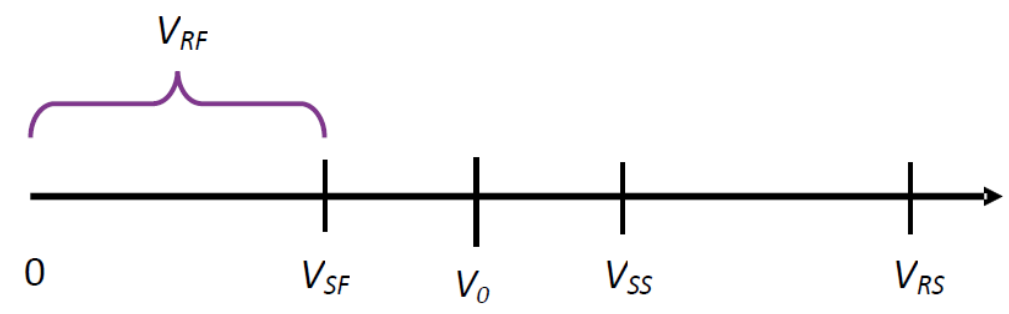

The CEO is paid in equity compensation consisting of some portion of options and some portion of stock. We normalize her salary to zero, since salary does not affect project choices. Payoffs for 
the CEO for each possible state of the world are as follows.

\begin{tabular}{|l|l|l|l|l|}
\hline Payoff & $V_{R S}$ & $V_{S S}$ & $V_{S F}$ & $V_{R F}$ \\
\hline Options & $\alpha\left(V_{R S}-V_{0}\right)$ & $\alpha\left(V_{S S}-V_{0}\right)$ & 0 & $-\frac{k}{V_{R F}}$ \\
\hline Stocks & $\beta V_{R S}$ & $\beta V_{S S}$ & $\beta V_{S F}$ & $-\frac{k}{V_{R F}}$ \\
\hline
\end{tabular}

For the case of compensating a CEO in stock, she then simply receives fraction $\beta$ of the firm, as long as there is no riskier failure. The fraction $\alpha$ measures the level of option compensation to the CEO. Typically executive option awards are issued close to "at the money," which, for our setting, means that options only have value after a successful project outcome. Thus, the CEO receives share $\alpha$ of the firm's increase in value, which happens only when a project- $R$ or $S$-succeeds.

Regardless of compensation structure, in the event of a riskier failure, $V_{R F}$ is realized and the executive faces a penalty of $\frac{-V_{R F}}{k}$. This can be thought of as lost future income or reputation for the CEO, as well as regulator fines and possible incarceration. This penalty is also increasing in the magnitude of failure.

A CEO compensated solely by options will choose $R$ when it has a positive expected payoff for him: $p \alpha\left(V_{R S}-V_{S S}\right)-(1-p) \frac{k}{V_{R F}}>0$. However, this will not be satisfied for some riskier projects since we may have a realization as low as $V_{R F}=0$. A CEO who is compensated only via stocks will choose $R$ iff $p \beta\left(V_{R S}-V_{S S}\right)-(1-p)\left(\beta V_{S F}+\frac{k}{V_{R F}}\right)>0$. Again, since we can have $V_{R F}=0$, the CEO will sometimes choose the safer project when paid all in stock.

For the CEO to choose the riskier project, it must be that the expected payoff from choosing $R$ is greater than the safer one, which can be written as

$$
(1-p)\left(\beta V_{S F}+\frac{k}{V_{R F}}\right) \leq p(\alpha+\beta)\left(V_{R S}-V_{S S}\right) .
$$

The firm, meanwhile, will choose some cutoff value $V_{R F}^{*}$ such that the CEO chooses all riskier projects $R$ when $\widetilde{V}_{R F} \geq V_{R F}^{*}$ and chooses $S$ otherwise, where $\widetilde{V}_{R F}$ is the realization of the random variable $V_{R F}$. This means that with a realization of $V_{R F}^{*}$, the firm is indifferent between the CEO choosing $R$ and $S$, which happens when $p\left(V_{R S}-V_{S S}\right)+(1-p)\left(V_{R F}^{*}-V_{S F}\right)=0$ : the expected benefit of choosing the riskier project equals the expected benefit of choosing the safer one. This implies that

$$
V_{R F}^{*}=\frac{-p\left(V_{R S}-V_{S S}\right)}{(1-p)}+V_{S F} .
$$

We refer to $V_{R F}^{*}$ as the risk-taking standard of the firm. We assume that the primitives of the model take on values such that $V_{R F}^{*}=\frac{-p\left(V_{R S}-V_{S S}\right)}{(1-p)}+V_{S F}>0$ so that we can rule out the case where the riskier project is preferred by the firm for any possible realization of $V_{R F}$; if this were true, riskier projects would always be chosen and there would be no project selection tension.

Finally, although riskier projects are not always preferred, they are still sometimes attractive. Formally, we assume that $\left(V_{0}-V_{S F}\right) \leq\left(V_{R S}-V_{S S}\right)$. This inequality means that the additional 
gain from the success of a riskier project is at least as great in magnitude as the loss from an unsuccessful safer project.

With these preliminaries, we can present the timeline of our stylized model:

1. The firm offers the CEO an equity pay contract (i.e., stocks and options);

2. The CEO observes the return characteristics of each project and chooses one;

3. A project succeeds (fails) at probability $p(1-p)$;

4. Payoffs are realized.

In the next section, we analyze the firm's decision problem and the ultimate contract offered, which we characterize in the following Lemma:

Lemma 1 CEOs receive options share $\alpha^{*}=\frac{V_{R F}^{*} \underline{\beta}+\frac{k}{V_{R F}^{*}}}{-V_{R F}^{*}+V_{S F}}$

Proof. See appendix

This $\alpha^{*}$ from Lemma 1 induces the CEO to implement the riskier project $R$ if and only if it has a higher expected net present value than the safer project $S$.

We next consider comparative statics to identify some testable empirical predictions. As shown in the next section, the relationship of the share of options $\alpha^{*}$ offered and a firm's risk standard $V_{R F}^{*}$ is nonmonotonic. However, for high-stakes environments (i.e., those settings for which the firm faces significant losses in the event of a riskier failure or the CEO faces a large penalty for a riskier failure) we have the following findings:

Proposition 2 Assuming high-stakes, an increase in option share $\alpha^{*}$ increases the chance $q(1-p)$ of riskier failure and decreases the expected value of the firm upon a riskier failure $E\left[V_{R F} \mid V_{R F}>V_{R F}^{*}\right]$.

Proof. See appendix

Thus, as a greater level of options are offered to the CEO, we expect the chance of a riskier failure to be greater and that such a failure will further reduce the value of the firm. To take our predictions to the data, we link the outcome variable $\alpha^{*}$ in our theory to a simple, observable variable. We call this new outcome variable the index $P$ and define it thus:

$$
P \equiv \frac{E\left[V_{\text {option }}\right]}{E\left[V_{\text {stock }}\right]+E\left[V_{\text {option }}\right]},
$$

which is the expected value of option awards divided by the expected value of option awards and stock awards. In other words, $P$ is the fraction of the value of equity compensation that the CEO receives in the form of options, which is readily identified in our data. Our final proposition provides our empirical predictions linked to $P$ : 
Proposition 3 Assuming high-stakes, an increase in the index $P$ results in

1. an increase in the odds of a riskier failure;

2. an increase in the expected cost of riskier failure $V_{0}-E\left[V_{R F} \mid V_{R F}>V_{R F}^{*}\right]$.

Proof. See appendix

\subsection{Proofs}

Lemma 1 CEOs receive options share $\alpha^{*}=\frac{V_{R F}^{*} \underline{\beta}+\frac{k}{V_{R F}^{*}}}{-V_{R F}^{*}+V_{S F}}$

Proof: The firm's problem is written as

$$
\begin{aligned}
& \underset{\alpha, \beta}{\max \pi} \equiv\left[\begin{array}{c}
q\left(p(1-\alpha-\beta) V_{R S}+p \alpha V_{o}+(1-p) E\left[V_{R F} \mid V_{R F}>V_{R F}^{*}\right]\right) \\
+(1-q)\left(p(1-\alpha-\beta) V_{S S}+p \alpha V_{o}+(1-p)\left((1-\beta) V_{S F}\right)\right)
\end{array}\right], \\
& \text { subject to } \frac{\beta+\frac{k}{V_{R F}^{*} V_{S F}}}{\alpha+\beta} \leq \frac{p}{(1-p)} \frac{V_{R S}-V_{S S}}{V_{S F}}, \alpha^{*}+\beta^{*} \leq 1 \text { and } \alpha^{*}, \beta^{*} \geq 0 \text {, }
\end{aligned}
$$

where we define $q \equiv \operatorname{Pr}\left(V_{R F} \geq V_{R F}^{*}\right)$. We proceed by assuming, as in Edmans and Liu (2011), that the firm induces the CEO to choose the first-best policy (i.e., choose $R$ if and only if its expected value is greater than $S$ ). This adds the constraint

$$
\frac{\beta+\frac{k}{V_{R F}^{*} V_{S F}}}{\alpha+\beta} \leq \frac{p}{(1-p)} \frac{V_{R S}-V_{S S}}{V_{S F}} .
$$

The conditions $\alpha^{*}+\beta^{*} \leq 1$ and $\alpha^{*}, \beta^{*} \geq 0$ ensure no more than the entire firm is given away and that only positive shares are given away.

The proof proceeds by first assuming that the principal could directly choose $V_{R F}^{*}$. Thus, conditional on $V_{R F}^{*}, q$ is fixed and it can readily be shown that

$$
\frac{\partial \pi}{\partial \alpha}<\frac{\partial \pi}{\partial \beta}<0
$$

which means that options are lower cost than stock as a form of executive compensation. However, the principal cannot directly choose $V_{R F}^{*}$ but instead must induce the CEO to take on some risk standard $V_{R F}^{*}$. This is achieved through choosing $\alpha$ and $\beta$ such that we meet inequality (7). Since it is costly for the firm to provide $\alpha$ and $\beta$, this constraint will bind. At $\alpha=\beta=0$, clearly (7) is not met. At the extreme, if $\frac{k}{V_{R F}^{*} V_{S F}}>\frac{p}{(1-p)} \frac{V_{R S}-V_{S S}}{V_{S F}}$, then $\alpha=1$ will be chosen, as $\alpha$ is less costly to the firm than $\beta$. This is the case where $k$ is so great that the firm cannot induce as much risk-taking as it would like and thus must settle for a higher $V_{R F}^{*}$ than desired. In this setting, it means that there is no relationship between changes in the primitives and $\alpha^{*}$ (i.e., because $\alpha^{*}=1$ regardless of parameter perturbations). Thus, to explore interior solutions we now focus on those cases where 


$$
\begin{aligned}
k & <\left(\frac{p}{(1-p)}\left(V_{R S}-V_{S S}\right)\right) V_{R F}^{*} \\
& =\left(\frac{p}{(1-p)}\left(V_{R S}-V_{S S}\right)\right)\left(\frac{-p\left(V_{R S}-V_{S S}\right)}{(1-p)}+V_{S F}\right) .
\end{aligned}
$$

Note that less $\alpha$ than $\beta$ is required to meet the inequality (7). Hence, since inequality (8) also shows that $\alpha$ is less costly than $\beta$, the firm will choose some $\alpha>0$ and $\beta=0$. However, if we assume some $\underline{\beta} \geq 0,{ }^{12}$ this means that the payment $\alpha^{*}$ is then

$$
\alpha^{*}=\frac{\underline{\beta}+\frac{k}{p} \frac{k}{V_{R F}^{*} V_{S F}}}{\frac{V_{R S}-V_{S S}}{(1-p)}}-\underline{\beta} .
$$

Recalling that $V_{R F}^{*}=\frac{-p\left(V_{R S}-V_{S S}\right)}{(1-p)}+V_{S F}$, with further rearranging, our expression for the $\alpha^{*}$ becomes

$$
\alpha^{*}=\frac{V_{R F}^{*} \underline{\beta}+\frac{k}{V_{R F}^{*}}}{-V_{R F}^{*}+V_{S F}}
$$

QED

Proposition 2 Assuming high-stakes (i.e., $\left.V_{S F}\left(V_{R F}^{*}\right)^{2} \underline{\beta}<k\left(V_{S F}-2 V_{R F}^{*}\right)\right)$, an increase in option share $\alpha^{*}$ increases the chance $q(1-p)$ of riskier failure and decreases the expected value of the firm upon a riskier failure $E\left[V_{R F} \mid V_{R F}>V_{R F}^{*}\right]$.

Proof: We first show how $\alpha^{*}$ changes as $V_{R F}^{*}$ changes. We will then link this result to show how changes in $V_{R F}^{*}$ affect $E\left[V_{R F} \mid V_{R F}>V_{R F}^{*}\right]$ and $q(1-p)$. We first consider a change in $V_{R F}^{*}$ originating from primitives other than $V_{S F}$; we will consider the case of $V_{S F}$ separately, since both $\alpha^{*}$ and $V_{R F}^{*}$ are a function of $V_{S F}$. Taking the derivative of $\alpha^{*}$ with respect to the risk standard yields

$$
\frac{\partial \alpha^{*}}{\partial V_{R F}^{*}}=\frac{2 k V_{R F}^{*}+V_{S F}\left(V_{R F}^{*}\right)^{2} \underline{\beta}-k V_{S F}}{\left(V_{R F}^{*}\right)^{2}\left(-V_{R F}^{*}+V_{S F}\right)^{2}}<>0 .
$$

The sign of $\frac{\partial \alpha^{*}}{\partial V_{R F}^{*}}$ is determined by the sign of $2 k V_{R F}^{*}+V_{S F}\left(V_{R F}^{*}\right)^{2} \underline{\beta}-k V_{S F}$. In other words,

\footnotetext{
${ }^{12}$ Kadan and Swinkles (2008) similarly find that firms should provide $100 \%$ options and no stocks-unless the firm has a substantial threat of bankruptcy, which does not generally include our empirical setting. Nonetheless, in practice we often observe that equity compensation consists of stock, in addition to options, even for large, stable firms. This could be driven by industry norms or a budget constraint for offering options. It could also be driven by convexity of cost in providing stocks and options, rather than the linear cost assumed above. Abstracting away from the source, we assume that there is some minimum $\underline{\beta}$ such that firms need to provide some amount of stock to managers. However, with $\beta=0$, our following comparative statics still hold.
} 
$\alpha^{*}$ is non-monotonic in risk-taking. We will have $\frac{\partial \alpha^{*}}{\partial V_{R F}^{*}}<0$ iff

$$
V_{S F}\left(V_{R F}^{*}\right)^{2} \underline{\beta}<k\left(V_{S F}-2 V_{R F}^{*}\right)
$$

If $\underline{\beta}=0$, then this condition simplifies to

$$
\frac{2 p\left(V_{R S}-V_{S S}\right)}{(1-p)}>V_{S F} .
$$

We refer to those settings where inequality (11) is met as the condition of high-stakes. This inequality is met when the risk standard $V_{R F}^{*}$ is sufficiently low, which means that the expected value of a riskier failure is sufficiently adverse. In addition, it also occurs with sufficiently high penalty $k$ to the CEO upon a riskier failure. If condition (11) is not met, then for this region of parameters, the comparative statics are simply reversed.

It is also the case that $\frac{d \alpha^{*}}{d V_{R F}^{*}}<0$. This can be seen by noting that

$$
\frac{d \alpha^{*}}{d V_{S F}}=\frac{\underline{\beta}+\frac{-k}{\left(V_{R F}^{*}\right)^{2}}}{\frac{p}{(1-p)}\left(V_{R S}-V_{S S}\right)} .
$$

This expression is negative when $\underline{\beta}+\frac{-k}{\left(V_{R F}^{*}\right)^{2}}<0$, which occurs under high-stakes. That is, if $V_{S F}\left(V_{R F}^{*}\right)^{2} \underline{\beta}<k\left(V_{S F}-2 V_{R F}^{*}\right)$ then $k>\left(V_{R F}^{*}\right)^{2} \underline{\beta}$, since $\frac{V_{S F}}{\left(V_{S F}-2 V_{R F}^{*}\right)}>1$.

Now consider how lowering the risk standard $V_{R F}^{*}$ affects $E\left[V_{R F} \mid V_{R F}>V_{R F}^{*}\right]$ and $q(1-p)$. It is trivial that $E\left[V_{R F} \mid V_{R F}>V_{R F}^{*}\right]$ decreases as $V_{R F}^{*}$ decreases: decreasing $V_{R F}^{*}$ lowers the lower bound of support of $V_{R F}$ while maintaining the same upper bound of support. It is not, however, trivial that $q(1-p)$ increases as $V_{R F}^{*}$ decreases; an increase in $p$ lowers the risk-standard $V_{R F}^{*}$, which means that $q$ increases while $(1-p)$ decreases. To determine the net effect, note that

$$
\frac{d}{d p}(q(1-p))=\frac{\left(V_{R S}-V_{S S}\right)}{V_{S F}}>0 .
$$

We now combine these three comparative statics to conclude that if a firm lowers its risk standard $V_{R F}^{*}$, option share $\alpha^{*}$ increases, the chance $q(1-p)$ of a riskier failure increases, and the expected value of the firm upon a riskier failure $E\left[V_{R F} \mid V_{R F}>V_{R F}^{*}\right]$ decreases.

QED

Proposition 3 Assuming riskier projects are high-stakes, an increase in the index $P$ results in

1. an increase in the odds of a riskier failure;

2. an increase in the expected cost of a riskier failure $V_{0}-E\left[V_{R F} \mid V_{R F}>V_{R F}^{*}\right]$.

Proof: We must show that any change in $P$ results in the same directional change in $\alpha^{*}$. Then, using Proposition 2, along with noting that an increased chance of an event also means increased odds and noting that the cost of a riskier failure (i.e., $V_{0}-E\left[V_{R F} \mid V_{R F}>V_{R F}^{*}\right]$ ) is strictly decreasing 
in $E\left[V_{R F} \mid V_{R F}>V_{R F}^{*}\right]$, the proof is complete. The expected value of options compensation can be written as

$$
\begin{aligned}
E\left[V_{\text {option }}\right] & =\alpha\left(q p\left(V_{R S}-V_{0}\right)+(1-q) p\left(V_{S S}-V_{0}\right)\right) \\
& =\alpha\left(q p V_{R S}+(1-q) p V_{S S}-p V_{0}\right)
\end{aligned}
$$

The expected value of compensation in stock is written as

$$
\begin{aligned}
E\left[V_{\text {stock }}\right] & =\beta\left(q p V_{R S}+(1-q)\left(p V_{S S}+(1-p) V_{S F}\right)\right) \\
& =\beta\left(q p V_{R S}+(1-q) p V_{S S}-p V_{0}+p V_{0}+(1-q)(1-p) V_{S F}\right)
\end{aligned}
$$

Now consider the index $P$, which we define as

$$
P \equiv \frac{E\left[V_{\text {option }}\right]}{E\left[V_{\text {stock }}\right]+E\left[V_{\text {option }}\right]} .
$$

First note that holding all other variables fixed, $P$ is increasing in $\alpha$ since $P<1$. Hence, we need only to show that $\frac{d}{d t} E\left[V_{\text {stock }}\right] \leq \frac{d}{d t} E\left[V_{\text {option }}\right]$, where $t$ is some parameter of $E\left[V_{\text {stock }}\right]$ or $E\left[V_{\text {option }}\right]$ that also increases $\alpha^{*}{ }^{13}$ Examination of $E\left[V_{\text {stock }}\right]$ and $E\left[V_{\text {option }}\right]$ shows that they are identical aside from $E\left[V_{\text {stock }}\right]$ containing an additional term $p V_{0}+(1-q)(1-p) V_{S F}$. We want to show that $\frac{d}{d t}\left[p V_{0}+(1-q)(1-p) V_{S F}\right] \leq 0$. We see that excluding $p, V_{S F}$ and all of the parameters that create $q$ all reduce the value of $p V_{0}+(1-q)(1-p) V_{S F}$ as they also increase $\alpha^{*}$. Thus, we must finally check that this term is (weakly) decreasing in $p$ (since $\alpha^{*}$ is increasing in $p$ ) :

$$
\begin{aligned}
& \frac{d}{d p}\left[p V_{0}+(1-q)(1-p) V_{S F}\right] \\
= & V_{0}-(1-q) V_{S F}-\frac{d q}{d p}(1-p) V_{S F} \\
= & V_{0}-\left(1-\frac{V_{S F}-V_{R F}^{*}}{V_{S F}}\right) V_{S F}-\frac{d q}{d p}(1-p) V_{S F} \\
= & V_{0}-\left(\frac{V_{R F}^{*}}{V_{S F}}\right) V_{S F}-\left(\frac{\frac{1}{(1-p)^{2}}\left(V_{R S}-V_{S S}\right)}{V_{S F}}\right)(1-p) V_{S F} \\
= & V_{0}-V_{R F}^{*}-\frac{1}{(1-p)}\left(V_{R S}-V_{S S}\right) \\
= & V_{0}-\left(\frac{-p\left(V_{R S}-V_{S S}\right)}{(1-p)}+V_{S F}\right)-\frac{1}{(1-p)}\left(V_{R S}-V_{S S}\right) \\
= & V_{0}-V_{S F}-\left(V_{R S}-V_{S S}\right) \\
\leq & 0
\end{aligned}
$$

\footnotetext{
${ }^{13}$ If a parameter (e.g., $\left.V_{S F}\right)$ decreases $\alpha^{*}$, then take $t$ to be its inverse (i.e., $\frac{1}{V_{S F}}$ ).
} 
where the final inequality follows from $\left(V_{0}-V_{S F}\right) \leq\left(V_{R S}-V_{S S}\right)$. QED. 


\section{Table 1: Summary Statistics}

\begin{tabular}{|c|c|c|c|c|c|c|c|c|}
\hline Variable & Obs & Mean & & Std. Dev. & & Min & & Max \\
\hline Event $(1 / 0)$ & 7705 & $15.04 \%$ & & $35.75 \%$ & & 0 & & 1 \\
\hline Total Fines & $1132 \$$ & 223,674 & $\$$ & $1,346,869$ & $\$$ & 1 & $\$$ & $25,000,000$ \\
\hline Index $\boldsymbol{P}$ of Equity Comp & 5999 & $75.08 \%$ & & $35.42 \%$ & & $0 \%$ & & $100 \%$ \\
\hline Total Compensation (mm) & $7628 \$$ & 6,257 & $\$$ & 12,758 & $\$$ & - & $\$$ & 600,347 \\
\hline KLD Environmental Strengths & 7705 & 0.17 & & 0.47 & & 0.00 & & 4.00 \\
\hline KLD Environmental Concerns & 7705 & 0.32 & & 0.80 & & 0.00 & & 6.00 \\
\hline Market Value & $7704 \$$ & 11,261 & $\$$ & 31,666 & $\$$ & 0 & $\$$ & 507,217 \\
\hline Market to Book Ratio & 7696 & 2.51 & & 1.62 & & 1.00 & & 28.88 \\
\hline Leverage & 7465 & 0.21 & & 0.18 & & 0.00 & & 4.91 \\
\hline Year & 7705 & $\mathrm{n} / \mathrm{a}$ & & $\mathrm{n} / \mathrm{a}$ & & 1996 & & 2006 \\
\hline
\end{tabular}

An event is a company's environmental failure that breaches environmental law

Total fines are total government fines for the environmental failure

Index $\boldsymbol{P}$ is the ratio of CEO total options compensation divided by total options and stock compensation for a given year KLD Environmental Strengths and Concerns are a firm's environmental performance ratings and are provided by KLD Analytics Compensation measures are from Execucomp and financial measures are from COMPUSTAT 
Table 2: The Relationship of $\boldsymbol{P}$ and Environmental Events: Logit Panel Model

\begin{tabular}{|c|c|c|c|c|}
\hline \multicolumn{5}{|c|}{ Dependent Variable: Environmental Incident $(1,0)$} \\
\hline & $(1)$ & $(2)$ & (3) & (4) \\
\hline Index $\boldsymbol{P}$ of Equity Comp at t-1 & $\begin{array}{c}0.4741^{* *} \\
(2.01)\end{array}$ & $\begin{array}{c}0.4538 * \\
(1.92)\end{array}$ & $\begin{array}{c}0.5506^{* *} \\
(2.50)\end{array}$ & $\begin{array}{c}0.5263^{* *} \\
(2.19)\end{array}$ \\
\hline Equity Comp $\%$ of Total Comp at t-1 & $\begin{array}{l}-0.582 \\
(-1.50)\end{array}$ & $\begin{array}{c}-0.5719 \\
(-1.45)\end{array}$ & $\begin{array}{l}-0.4946 \\
(-1.22)\end{array}$ & $\begin{array}{c}-0.0205 \\
(-0.05)\end{array}$ \\
\hline Total Compensation at t-1 & $\begin{array}{l}0.0000 \\
(0.52)\end{array}$ & $\begin{array}{l}0.0000 \\
(0.56)\end{array}$ & $\begin{array}{l}0.0000 \\
(0.31)\end{array}$ & $\begin{array}{l}0.0000 \\
(0.39)\end{array}$ \\
\hline KLD Env Strengths at t-1 & & $\begin{array}{c}-0.0287 \\
(-0.15)\end{array}$ & $\begin{array}{c}-0.0011 \\
(-0.01)\end{array}$ & $\begin{array}{c}-0.0223 \\
(-0.12)\end{array}$ \\
\hline KLD Env Concerns at t-1 & & $\begin{array}{l}-0.0958 \\
(-0.73) \\
\end{array}$ & $\begin{array}{c}-0.0887 \\
(-0.63) \\
\end{array}$ & $\begin{array}{c}-0.0464 \\
(-0.31) \\
\end{array}$ \\
\hline Firm Fixed Effects & Yes & Yes & Yes & Yes \\
\hline Env Controls & No & Yes & Yes & Yes \\
\hline Financial Controls & No & No & Yes & Yes \\
\hline Year Fixed Effects & No & No & No & Yes \\
\hline $\mathrm{N}$ & 1750 & 1750 & 1715 & 1715 \\
\hline
\end{tabular}

z statistics reported in parentheses

Standard errors are calculated via bootstrap method (400 repetitions)

$* \mathrm{p}<0.10 * * \mathrm{p}<.05 * * * \mathrm{p}<.01$ 
Table 3: The Relationship of $\boldsymbol{P}$ and Environmental Events: Linear Panel Model

\begin{tabular}{|c|c|c|c|c|}
\hline \multicolumn{5}{|c|}{ Dependent Variable: Environmental Incident $(1,0)$} \\
\hline & $(1)$ & $(2)$ & $(3)$ & $(4)$ \\
\hline Index $\boldsymbol{P}$ of Equity Comp at t-1 & $\begin{array}{c}0.0497^{* *} \\
(2.03)\end{array}$ & $\begin{array}{c}0.0478 * \\
(1.94)\end{array}$ & $\begin{array}{c}0.0563^{* *} \\
(2.26)\end{array}$ & $\begin{array}{c}0.0492^{*} \\
(1.89)\end{array}$ \\
\hline Equity Comp $\%$ of Total Comp at $\mathrm{t}-1$ & $\begin{array}{c}-0.0552 \\
(-1.44)\end{array}$ & $\begin{array}{c}-0.0538 \\
(-1.40)\end{array}$ & $\begin{array}{c}-0.0515 \\
(-1.29)\end{array}$ & $\begin{array}{l}-0.0070 \\
(-0.18)\end{array}$ \\
\hline Total Compensation at t-1 & $\begin{array}{l}0.0000 \\
(0.66)\end{array}$ & $\begin{array}{l}0.0000 \\
(0.69)\end{array}$ & $\begin{array}{l}0.0000 \\
(0.46)\end{array}$ & $\begin{array}{l}0.0000 \\
(0.84)\end{array}$ \\
\hline KLD Env Strengths at t-1 & & $\begin{array}{l}-0.0046 \\
(-0.14)\end{array}$ & $\begin{array}{c}-0.0032 \\
(-0.10)\end{array}$ & $\begin{array}{l}-0.0058 \\
(-0.19)\end{array}$ \\
\hline KLD Env Concerns at t-1 & & $\begin{array}{l}-0.0207 \\
(-0.75) \\
\end{array}$ & $\begin{array}{c}-0.0199 \\
(-0.72) \\
\end{array}$ & $\begin{array}{l}-0.0129 \\
(-0.48) \\
\end{array}$ \\
\hline Firm Fixed Effects & Yes & Yes & Yes & Yes \\
\hline Env Controls & No & Yes & Yes & Yes \\
\hline Financial Controls & No & No & Yes & Yes \\
\hline Year Fixed Effects & No & No & No & Yes \\
\hline $\mathrm{N}$ & 5108 & 5108 & 4938 & 4938 \\
\hline
\end{tabular}

t statistics reported in parentheses

standard errors are clustered at the firm-level

${ }^{*} p<0.10{ }^{* *} p<.05{ }^{* * *} p<.01$ 
Table 4: Relationship of $P$ and High vs. Low Magnitude Events: Logit Panel Model

\begin{tabular}{|c|c|c|c|}
\hline \multicolumn{4}{|c|}{ Dependent Variable: Environmental Incident $(1,0)$} \\
\hline & $(1)$ & $(2)$ & (3) \\
\hline \multirow[t]{2}{*}{ Index $\boldsymbol{P}$ of Equity Comp at t-1 } & $0.5263^{* *}$ & -0.0080 & $1.1344 * *$ \\
\hline & $(2.17)$ & $(-0.02)$ & $(2.53)$ \\
\hline \multirow[t]{2}{*}{ Equity Comp $\%$ of Total Comp at t-1 } & -0.0205 & -0.4442 & 1.2405 \\
\hline & $(-0.05)$ & $(-0.69)$ & $(1.60)$ \\
\hline \multirow[t]{2}{*}{ Total Compensation at t-1 } & 0.0000 & 0.0000 & -0.0000 \\
\hline & $(0.34)$ & $(0.39)$ & $(-0.80)$ \\
\hline \multirow[t]{2}{*}{ KLD Env Strengths at t-1 } & -0.0223 & -0.2229 & -0.3810 \\
\hline & $(-0.11)$ & $(-0.92)$ & $(-1.51)$ \\
\hline \multirow[t]{2}{*}{ KLD Env Concerns at t-1 } & -0.0464 & -0.0223 & $-0.2872^{*}$ \\
\hline & $(-0.33)$ & $(-0.11)$ & $(-1.73)$ \\
\hline Incident Magnitude & All & 4th Q & 1st Q \\
\hline Firm Fixed Effects & Yes & Yes & Yes \\
\hline Env Controls & Yes & Yes & Yes \\
\hline Year Fixed Effects & Yes & Yes & Yes \\
\hline Financial Controls & Yes & Yes & Yes \\
\hline $\mathrm{N}$ & 1715 & 895 & 749 \\
\hline
\end{tabular}


Table 5: Relationship of $\boldsymbol{P}$ and Large vs. Small Magnitude Events: Linear Panel Model

\begin{tabular}{|c|c|c|c|}
\hline \multicolumn{4}{|c|}{ Dependent Variable: Environmental Incident $(1,0)$} \\
\hline & (1) & (2) & (3) \\
\hline \multirow[t]{2}{*}{ Index $\boldsymbol{P}$ of Equity Comp at t-1 } & $0.0492 *$ & 0.0019 & $0.0388^{* *}$ \\
\hline & $(1.89)$ & $(0.11)$ & $(2.30)$ \\
\hline \multirow[t]{2}{*}{ Equity Comp $\%$ of Total Comp at t-1 } & -0.0070 & -0.0179 & 0.0297 \\
\hline & $(-0.18)$ & $(-0.76)$ & $(1.27)$ \\
\hline \multirow[t]{2}{*}{ Total Compensation at t-1 } & 0.0000 & 0.0000 & -0.0000 \\
\hline & $(0.84)$ & $(0.66)$ & $(-0.84)$ \\
\hline \multirow[t]{2}{*}{ KLD Env Strengths at t-1 } & -0.0058 & -0.0129 & -0.0230 \\
\hline & $(-0.19)$ & $(-0.77)$ & $(-1.19)$ \\
\hline \multirow[t]{2}{*}{ KLD Env Concerns at t-1 } & -0.0129 & -0.0013 & -0.0252 \\
\hline & $(-0.48)$ & $(-0.10)$ & $(-1.36)$ \\
\hline Incident Magnitude & All & 4th Q & 1 st $Q$ \\
\hline Firm Fixed Effects & Yes & Yes & Yes \\
\hline Env Controls & Yes & Yes & Yes \\
\hline Year Fixed Effects & Yes & Yes & Yes \\
\hline Financial Controls & Yes & Yes & Yes \\
\hline $\mathrm{N}$ & 4938 & 4938 & 4938 \\
\hline
\end{tabular}

t statistics reported in parentheses

standard errors are clustered at the firm-level

$* p<0.10 * * p<.05 * * * p<.01$ 
Table 6: Falsification Test of the Relationship of $\boldsymbol{P}$ and Incident Rates

\begin{tabular}{lcccc}
\hline \multicolumn{5}{c}{ Dependent Variable: Environmental Incident $(1,0)$} \\
& $(1)$ & $(2)$ & $(3)$ & $(4)$ \\
\hline Index $\boldsymbol{P}$ of Equity Comp at t+1 & 0.2379 & 0.2310 & 0.2287 & -0.2439 \\
& $(0.93)$ & $(0.94)$ & $(0.92)$ & $(-0.90)$ \\
& & & & \\
Equity Comp \% of Total Comp at t-1 & -0.4983 & -0.4835 & -0.4057 & 0.0547 \\
& $(-1.37)$ & $(-1.37)$ & $(-1.10)$ & $(0.15)$ \\
& & & & \\
Total Compensation at t-1 & 0.0000 & 0.0000 & 0.0000 & 0.0000 \\
& $(0.70)$ & $(0.59)$ & $(0.47)$ & $(0.68)$ \\
& & & & \\
KLD Env Strengths at t-1 & & -0.0761 & -0.0101 & -0.2137 \\
& & $(-0.27)$ & $(-0.03)$ & $(-0.82)$ \\
& & -0.0833 & -0.0853 & -0.0361 \\
KLD Env Concerns at t-1 & & $(-0.52)$ & $(-0.53)$ & $(-0.21)$ \\
\hline & & & & \\
Firm Fixed Effects & Yes & Yes & Yes & Yes \\
Env Controls & No & Yes & Yes & Yes \\
Financial Controls & No & No & Yes & Yes \\
Year Fixed Effects & No & No & No & Yes \\
\hline \multirow{2}{*}{ N } & 1401 & 1401 & 1377 & 1377 \\
\hline
\end{tabular}

z statistics reported in parentheses

Standard errors are calculated via bootstrap method (400 repetitions)

$* \mathrm{p}<0.10 * * \mathrm{p}<.05 * * * \mathrm{p}<.01$ 


\section{Table 7: Additional Compensation Controls}

\begin{tabular}{|c|c|c|c|c|}
\hline \multicolumn{5}{|c|}{ Dependent Variable: Top Quartile Environmental Incident $(1,0)$} \\
\hline & $(1)$ & $(2)$ & (3) & $(4)$ \\
\hline Index $\boldsymbol{P}$ of Equity Comp at $\mathrm{t}-1$ & $\begin{array}{c}1.1344^{* *} \\
(2.39)\end{array}$ & $\begin{array}{c}1.0940 * * \\
(2.34)\end{array}$ & $\begin{array}{c}1.5370 * * * \\
(2.86)\end{array}$ & $\begin{array}{c}1.3681^{* * *} \\
(2.64)\end{array}$ \\
\hline Ln(Total Stock Value) at t-1 & & $\begin{array}{l}0.0816 \\
(0.63)\end{array}$ & & \\
\hline Ln(Total Option Value) at t-1 & & $\begin{array}{c}-0.0373 \\
(-0.62)\end{array}$ & & \\
\hline Total Delta at t-1 & & & $\begin{array}{c}-0.0004 \\
(-0.94)\end{array}$ & \\
\hline Total Vega at t-1 & & & & $\begin{array}{c}0.0011 \\
(0.65) \\
\end{array}$ \\
\hline Firm Fixed Effects & Yes & Yes & Yes & Yes \\
\hline Env Controls & Yes & Yes & Yes & Yes \\
\hline Financial Controls & Yes & Yes & Yes & Yes \\
\hline Year Fixed Effects & Yes & Yes & Yes & Yes \\
\hline $\mathrm{N}$ & 749 & 705 & 724 & 724 \\
\hline
\end{tabular}

z statistics reported in parentheses

Standard errors are calculated via bootstrap method (400 repetitions)

$* p<0.10 * * p<.05 * * * p<.01$ 
Table 8: Relationship of $\boldsymbol{P}$ and Magnitude of Environmental Events

\begin{tabular}{|c|c|c|c|c|}
\hline \multicolumn{5}{|c|}{ Dependent Variable: In(1+total government fines) } \\
\hline & (1) & $(2)$ & (3) & (4) \\
\hline Index $\boldsymbol{P}$ of Equity Comp at t-1 & $\begin{array}{c}0.9963^{* *} \\
(2.28)\end{array}$ & $\begin{array}{c}0.9607^{* *} \\
(2.16)\end{array}$ & $\begin{array}{c}0.9967^{* *} \\
(2.21)\end{array}$ & $\begin{array}{c}0.8395^{*} \\
(1.88)\end{array}$ \\
\hline Equity Comp $\%$ of Total Comp at t-1 & $\begin{array}{l}0.5022 \\
(0.64)\end{array}$ & $\begin{array}{l}0.5219 \\
(0.67)\end{array}$ & $\begin{array}{l}0.6176 \\
(0.78)\end{array}$ & $\begin{array}{l}0.6379 \\
(0.78)\end{array}$ \\
\hline Total Compensation at t-1 & $\begin{array}{l}-0.0000 \\
(-0.95)\end{array}$ & $\begin{array}{c}-0.0000 \\
(-0.78)\end{array}$ & $\begin{array}{c}-0.0000 \\
(-0.48)\end{array}$ & $\begin{array}{l}-0.0000 \\
(-0.44)\end{array}$ \\
\hline KLD Env Strengths at t-1 & & $\begin{array}{c}-0.1435 \\
(-0.47)\end{array}$ & $\begin{array}{c}-0.1470 \\
(-0.49)\end{array}$ & $\begin{array}{l}-0.1184 \\
(-0.39)\end{array}$ \\
\hline KLD Env Concerns at t-1 & & $\begin{array}{c}-0.2292 \\
(-0.94)\end{array}$ & $\begin{array}{c}-0.2349 \\
(-0.94)\end{array}$ & $\begin{array}{l}-0.1555 \\
(-0.63) \\
\end{array}$ \\
\hline Firm Fixed Effects & Yes & Yes & Yes & Yes \\
\hline Env Controls & No & Yes & Yes & Yes \\
\hline Financial Controls & No & No & Yes & Yes \\
\hline Year Fixed Effects & No & No & No & Yes \\
\hline $\mathrm{N}$ & 820 & 820 & 813 & 813 \\
\hline
\end{tabular}

t statistics reported in parentheses

standard errors are clustered at the firm-level

${ }^{*} p<0.10{ }^{* *} p<.05{ }^{* * *} p<.01$ 
Table 9: Relationship of $\boldsymbol{P}$ and Magnitude of Events (Large vs. Small)

\begin{tabular}{|c|c|c|c|}
\hline \multicolumn{4}{|c|}{ Dependent Variable: $\operatorname{In}(1+$ total government fines) } \\
\hline & $(1)$ & $(2)$ & $(3)$ \\
\hline \multirow[t]{2}{*}{ Index $\boldsymbol{P}$ of Equity Comp at t-1 } & $0.8395^{*}$ & 0.2824 & $1.3531^{* *}$ \\
\hline & $(1.88)$ & $(0.52)$ & $(2.22)$ \\
\hline \multirow[t]{2}{*}{ Equity Comp \% of Total Comp at t-1 } & 0.6379 & -0.6099 & 0.5767 \\
\hline & $(0.78)$ & $(-0.64)$ & $(0.73)$ \\
\hline \multirow[t]{2}{*}{ Total Compensation at t-1 } & -0.0000 & 0.0000 & -0.0000 \\
\hline & $(-0.44)$ & $(0.05)$ & $(-0.76)$ \\
\hline \multirow[t]{2}{*}{ KLD Env Strengths at t-1 } & -0.1184 & -0.2716 & -0.2861 \\
\hline & $(-0.39)$ & $(-0.91)$ & $(-1.00)$ \\
\hline \multirow[t]{2}{*}{ KLD Env Concerns at t-1 } & -0.1555 & 0.0779 & 0.0134 \\
\hline & $(-0.63)$ & $(0.42)$ & $(0.04)$ \\
\hline Incident Magnitude & All & $<$ Median & >Median \\
\hline Firm Fixed Effects & Yes & Yes & Yes \\
\hline Env Controls & Yes & Yes & Yes \\
\hline Year Fixed Effects & Yes & Yes & Yes \\
\hline Financial Controls & Yes & Yes & Yes \\
\hline $\mathrm{N}$ & 813 & 410 & 403 \\
\hline
\end{tabular}

t statistics reported in parentheses

standard errors are clustered at the firm-level

${ }^{*} p<0.10 * * p<.05 * * * p<.01$ 
Table 10: Incentive Effects on Incident Rates

\begin{tabular}{|c|c|c|c|c|c|c|}
\hline \multicolumn{7}{|c|}{ Dependent Variable: Environmental Incident $(1,0)$} \\
\hline & $(1)$ & $(2)$ & (3) & $(4)$ & $(5)$ & $(6)$ \\
\hline \multirow[t]{2}{*}{ Index $\boldsymbol{P}$ of Equity Comp at t-1 } & 0.2646 & -0.1808 & $1.2633^{* *}$ & 0.0262 & -0.0057 & $0.0403^{* *}$ \\
\hline & $(0.98)$ & $(-0.40)$ & $(2.51)$ & $(0.92)$ & $(-0.26)$ & $(2.50)$ \\
\hline \multirow[t]{2}{*}{ Equity Comp $\%$ of Total Comp at $\mathrm{t}-1$} & 0.0973 & -0.1382 & 1.5453 & 0.0052 & -0.0029 & 0.0255 \\
\hline & $(0.20)$ & $(-0.18)$ & $(1.53)$ & $(0.12)$ & $(-0.11)$ & $(0.93)$ \\
\hline \multirow[t]{2}{*}{ Total Compensation at t-1 } & -0.0000 & 0.0000 & -0.0000 & 0.0000 & 0.0000 & -0.0000 \\
\hline & $(-0.03)$ & $(0.32)$ & $(-0.70)$ & $(0.25)$ & $(0.58)$ & $(-0.75)$ \\
\hline \multirow[t]{2}{*}{ KLD Env Strengths at t-1 } & -0.2304 & $-0.7859 * *$ & -0.3553 & -0.0223 & $-0.0378 *$ & -0.0212 \\
\hline & $(-0.90)$ & $(-2.10)$ & $(-1.14)$ & $(-0.63)$ & $(-1.91)$ & $(-0.91)$ \\
\hline \multirow[t]{2}{*}{ KLD Env Concerns at t-1 } & $-0.3101^{*}$ & -0.2413 & $-0.5099 * *$ & -0.0406 & -0.0168 & -0.0381 \\
\hline & $(-1.75)$ & $(-0.90)$ & $(-2.32)$ & $(-1.33)$ & $(-0.87)$ & $(-1.64)$ \\
\hline Model & Logit FE & Logit FE & Logit FE & Linear FE & Linear FE & Linear FE \\
\hline Incident Magnitude & All & 4th Q & 1st Q & All & 4th Q & 1st $\mathrm{Q}$ \\
\hline Firm Fixed Effects & Yes & Yes & Yes & Yes & Yes & Yes \\
\hline Env Controls & Yes & Yes & Yes & Yes & Yes & Yes \\
\hline Year Fixed Effects & Yes & Yes & Yes & Yes & Yes & Yes \\
\hline Financial Controls & Yes & Yes & Yes & Yes & Yes & Yes \\
\hline $\mathrm{N}$ & 1297 & 635 & 538 & 4938 & 4938 & 4938 \\
\hline
\end{tabular}

$z$ or $t$ statistics reported in parentheses for logit and linear models, respectively Logit panel standard errors are calculated via bootstrap method (400 repetitions)

Linear panel standard errors are clustered at the firm-ceo pair level

${ }^{*} \mathrm{p}<0.10 * * \mathrm{p}<.05 * * * \mathrm{p}<.01$ 
Table 11: Incentive Effects on Event Magnitudes

\begin{tabular}{|c|c|c|c|c|}
\hline \multicolumn{5}{|c|}{ Dependent Variable: $\ln (1+$ total government fines) } \\
\hline & (1) & (2) & (3) & (4) \\
\hline Index $\boldsymbol{P}$ of Equity Comp at t-1 & $\begin{array}{c}1.0721^{*} \\
(1.81)\end{array}$ & $\begin{array}{c}1.0595^{*} \\
(1.77)\end{array}$ & $\begin{array}{c}1.0720^{*} \\
(1.80)\end{array}$ & $\begin{array}{l}0.9036 \\
(1.50)\end{array}$ \\
\hline Equity Comp \% of Total Comp at t-1 & $\begin{array}{c}-0.0891 \\
(-0.08)\end{array}$ & $\begin{array}{c}-0.0538 \\
(-0.05)\end{array}$ & $\begin{array}{c}-0.0707 \\
(-0.06)\end{array}$ & $\begin{array}{c}-0.1659 \\
(-0.15)\end{array}$ \\
\hline Total Compensation at $\mathrm{t}-1$ & $\begin{array}{l}0.0000 \\
(0.32)\end{array}$ & $\begin{array}{l}0.0000 \\
(0.34)\end{array}$ & $\begin{array}{l}0.0000 \\
(0.31)\end{array}$ & $\begin{array}{l}0.0000 \\
(0.36)\end{array}$ \\
\hline KLD Env Strengths at $\mathrm{t}-1$ & & $\begin{array}{l}0.0608 \\
(0.14)\end{array}$ & $\begin{array}{l}0.0335 \\
(0.08)\end{array}$ & $\begin{array}{l}0.0851 \\
(0.19)\end{array}$ \\
\hline KLD Env Concerns at t- 1 & & $\begin{array}{c}-0.1534 \\
(-0.53) \\
\end{array}$ & $\begin{array}{c}-0.1733 \\
(-0.60) \\
\end{array}$ & $\begin{array}{c}-0.1711 \\
(-0.62) \\
\end{array}$ \\
\hline Firm-CEO Fixed Effects & Yes & Yes & Yes & Yes \\
\hline Env Controls & No & Yes & Yes & Yes \\
\hline Financial Controls & No & No & Yes & Yes \\
\hline Year Fixed Effects & No & No & No & Yes \\
\hline $\mathrm{N}$ & 726 & 726 & 722 & 722 \\
\hline
\end{tabular}

t statistics reported in parentheses

standard errors are clustered at the firm-ceo pair level

$* \mathrm{p}<0.10 * * \mathrm{p}<.05 * * * \mathrm{p}<.01$ 
Table 12: The Relationship of $P$ and Financial Accounting Events: Logit Panel Model

\begin{tabular}{|c|c|c|c|}
\hline \multicolumn{4}{|c|}{ Dependent Variable: Accounting Incident $(1,0)$} \\
\hline & $(1)$ & $(2)$ & (3) \\
\hline \multirow[t]{2}{*}{ Index $\boldsymbol{P}$ of Equity Comp at t-1 } & $2.1446 * *$ & $2.4711^{* * *}$ & $1.5317^{* *}$ \\
\hline & (3.27) & $(3.61)$ & (2.14) \\
\hline \multirow[t]{2}{*}{ Equity Comp $\%$ of Total Comp at $\mathrm{t}-1$} & 0.5291 & 1.0544 & 0.8040 \\
\hline & $(0.86)$ & $(1.59)$ & $(1.27)$ \\
\hline \multirow[t]{2}{*}{ Total Compensation at t-1 } & 0.0000 & 0.0000 & 0.0000 \\
\hline & $(0.32)$ & $(0.11)$ & $(0.05)$ \\
\hline Firm Random Effects & Yes & Yes & Yes \\
\hline Financial Controls & No & Yes & Yes \\
\hline Year Fixed Effects & No & No & Yes \\
\hline $\mathrm{N}$ & 13586 & 13098 & 13098 \\
\hline \multicolumn{4}{|c|}{ z statistics reported in parentheses } \\
\hline \multicolumn{4}{|c|}{ standard errors are bootstrap (400 repetitions) } \\
\hline \multicolumn{4}{|c|}{ accounting incident is a restatement that is investigated by the SEC } \\
\hline${ }^{*} p<0.10^{* *} p$ & $* * p<.01$ & & \\
\hline
\end{tabular}


Table 13: The Relationship of $\boldsymbol{P}$ and Financial Accounting Events: Linear Panel Model

\begin{tabular}{lccc|}
\hline \multicolumn{4}{|c|}{ Dependent Variable: Accounting Incident $(1,0)$} \\
& $(1)$ & $(2)$ & $(3)$ \\
\hline Index $\boldsymbol{P}$ of Equity Comp at t-1 & $0.0058^{* * *}$ & $0.0066^{* * *}$ & $0.0037^{* * *}$ \\
& $(4.72)$ & $(4.74)$ & $(2.94)$ \\
& & & \\
Equity Comp \% of Total Comp at t-1 & 0.0013 & 0.0029 & 0.0025 \\
& $(0.53)$ & $(1.11)$ & $(0.93)$ \\
& & & \\
Total Compensation at t-1 & 0.0000 & 0.0000 & 0.0000 \\
& $(0.75)$ & $(0.58)$ & $(0.43)$ \\
\hline & & & \\
Firm Random Effects & Yes & Yes & Yes \\
Financial Controls & No & Yes & Yes \\
Year Fixed Effects & No & No & Yes \\
\hline & 13586 & 13098 & 13098 \\
\hline$N$
\end{tabular}

t statistics reported in parentheses

standard errors are clustered at the firm level

accounting incident is a restatement that is investigated by the SEC

$* \mathrm{p}<0.10 * * \mathrm{p}<.05 * * * \mathrm{p}<.01$ 
Table 14: The Effect of Policy Changes on Potential Accounting Misconduct

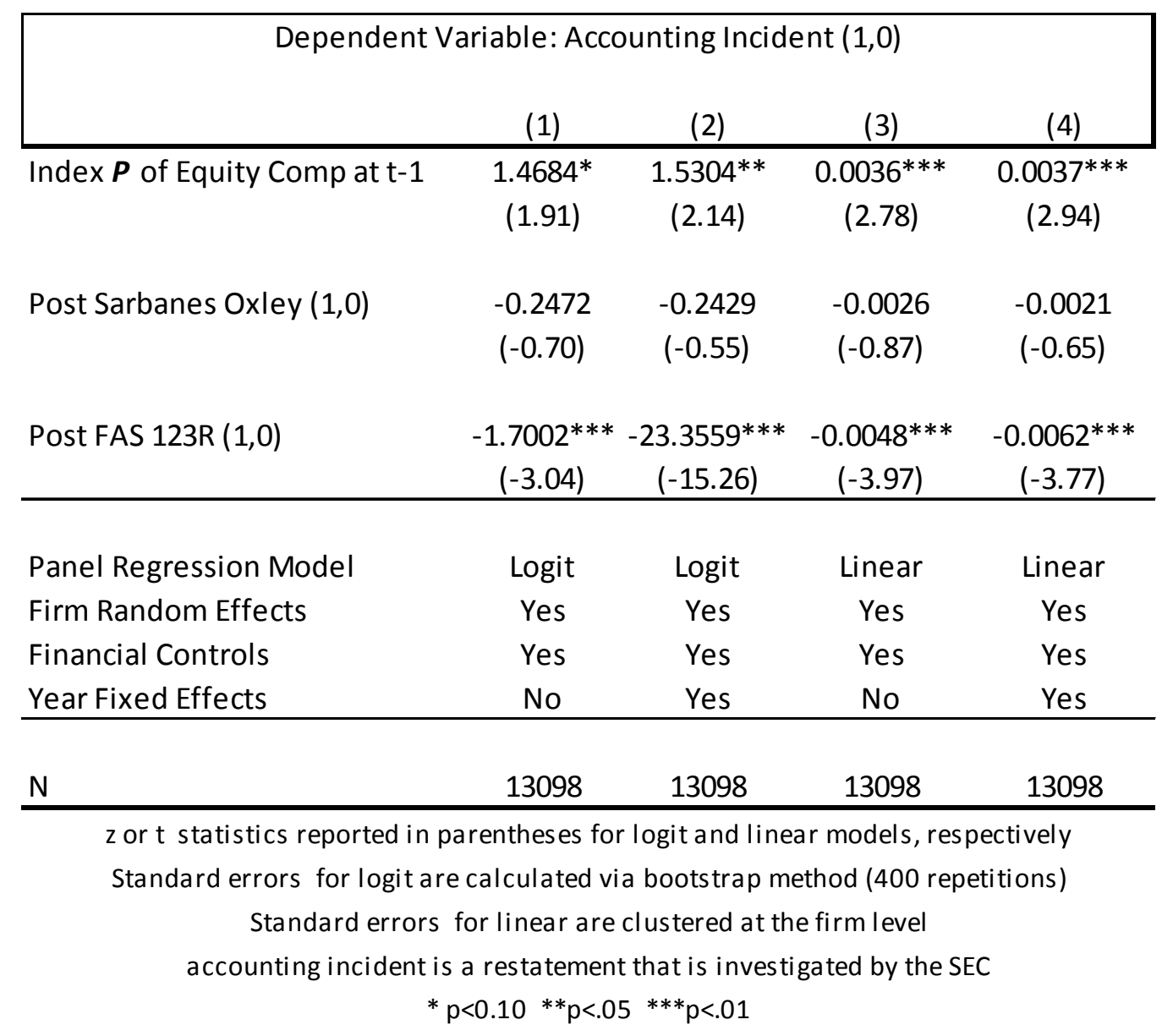


Table 15: Relationship of $P$ and Magnitude of Financial Accounting Events

\begin{tabular}{lcccc}
\hline \multicolumn{5}{c}{ Dependent Variable: In(1+abs(negative earnings restatement)) } \\
& $(1)$ & $(2)$ & $(3)$ & $(4)$ \\
\hline Index $\boldsymbol{P}$ of Equity Comp at t-1 & $0.6489^{* *}$ & $0.6524^{* *}$ & 0.4869 & 0.5429 \\
& $(2.15)$ & $(2.29)$ & $(1.62)$ & $(1.63)$ \\
& & & & \\
Equity Comp \% of Total Comp at t-1 & 0.7070 & $0.7724^{*}$ & $0.7648^{*}$ & 0.6918 \\
& $(1.45)$ & $(1.73)$ & $(1.75)$ & $(1.23)$ \\
& & & & \\
Total Compensation at t-1 & $0.0000^{* * *}$ & $0.0000^{*}$ & $0.0000^{*}$ & $0.0000^{* *}$ \\
& $(3.71)$ & $(1.95)$ & $(1.81)$ & $(2.53)$ \\
\hline & & & & \\
Regression Model & OLS & OLS & OLS & OLS \\
Financial Controls & No & Yes & Yes & Yes \\
Year Fixed Effects & No & No & Yes & Yes \\
Industry Controls & No & No & no & Yes \\
\hline & & & & \\
$N$ & 283 & 274 & 274 & 274 \\
\hline
\end{tabular}

t statistics reported in parentheses

robust standard errors

${ }^{*} p<0.10{ }^{* *} p<.05{ }^{* * *} p<.01$ 